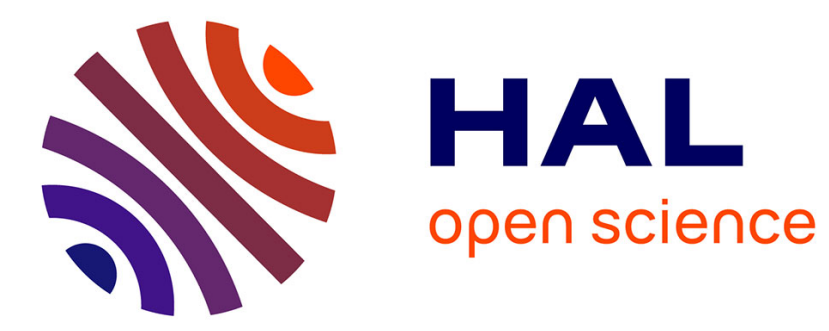

\title{
Evolution of cementite composition along the processing of cold-rolled and annealed Dual-Phase steels
}

Marc Moreno, Julien Teixeira, Jaafar Ghanbaja, Frédéric Bonnet, Sébastien Allain

\section{- To cite this version:}

Marc Moreno, Julien Teixeira, Jaafar Ghanbaja, Frédéric Bonnet, Sébastien Allain. Evolution of cementite composition along the processing of cold-rolled and annealed Dual-Phase steels. Materialia, 2019, 6, pp.100179. 10.1016/j.mtla.2018.100179 . hal-02389280

\section{HAL Id: hal-02389280 \\ https://hal.univ-lorraine.fr/hal-02389280}

Submitted on 22 Oct 2021

HAL is a multi-disciplinary open access archive for the deposit and dissemination of scientific research documents, whether they are published or not. The documents may come from teaching and research institutions in France or abroad, or from public or private research centers.
L'archive ouverte pluridisciplinaire HAL, est destinée au dépôt et à la diffusion de documents scientifiques de niveau recherche, publiés ou non, émanant des établissements d'enseignement et de recherche français ou étrangers, des laboratoires publics ou privés.

\section{(ㄷ)(1) $\$$}

Distributed under a Creative Commons Attribution - NonCommerciall 4.0 International 


\section{Evolution of cementite composition along 2 the processing of cold-rolled and annealed 3 Dual-Phase steels}

4 Marc Morenol, Julien Teixeira ${ }^{1}$, Jaafar Ghanbaja ${ }^{1}$, Frédéric Bonnet ${ }^{2}$, Sébastien

5 Allain $^{1}$

6

$7 \quad{ }^{1}$ Institut Jean Lamour, UMR CNRS UL 7198, Nancy, France

$8 \quad{ }^{2}$ ArcelorMittal Maizières Research SA, Automotive Products Research Center, Maizières les Metz,

9 France

Mn Composition gradients in cementite after coiling operation

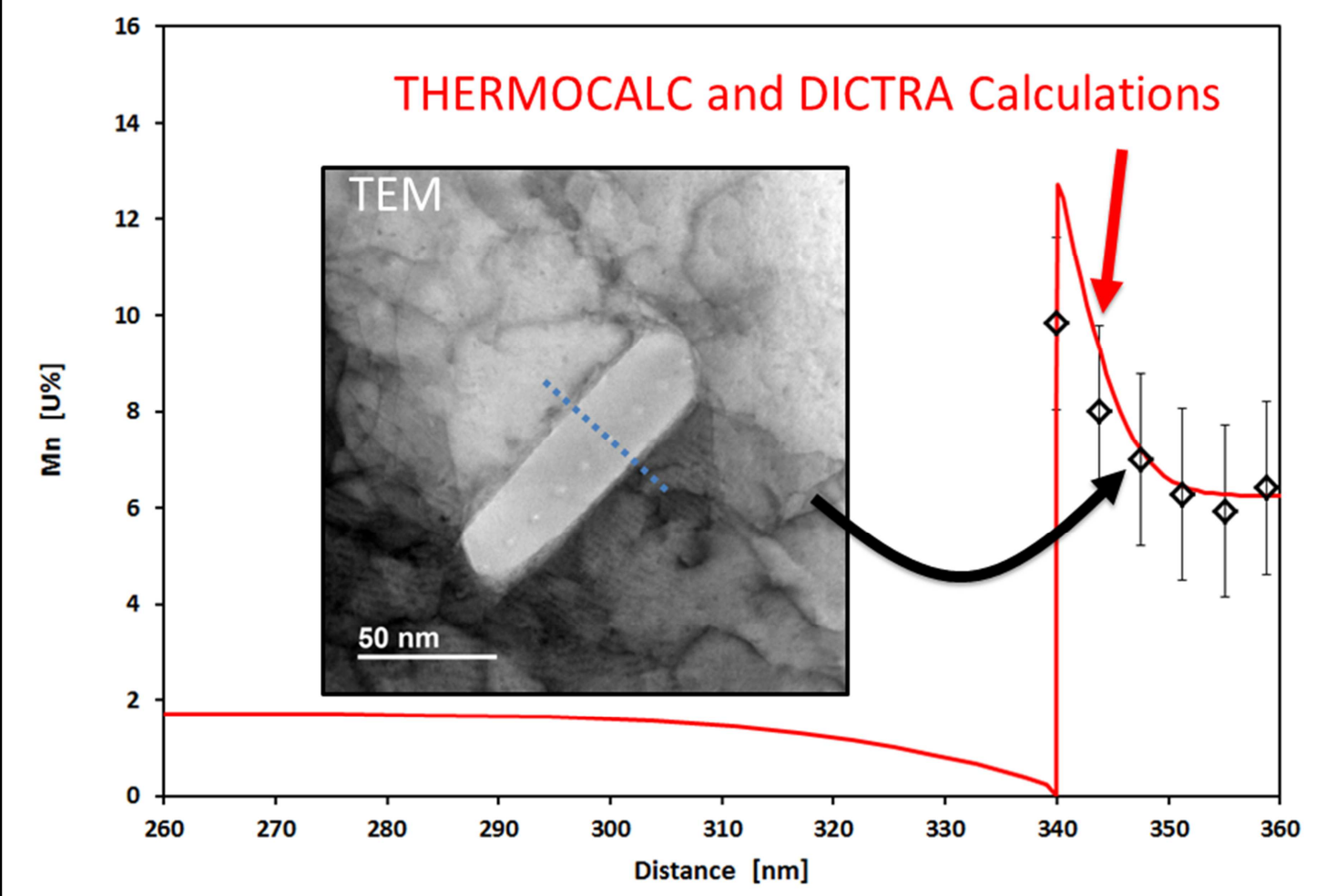




\section{Highlights}

- Cementite composition in ferrite-pearlite steels is measured and modeled all along industrial Dual-Phase steels' manufacturing route

- Pearlite transformation occurs with partition of manganese as it is governed by two simultaneous local equilibria at growing fronts

- Manganese diffusion coefficient in pearlite has been reassessed on experimental basis

- Cementite enrichment in manganese is the key to understand inheritance effects in Dual-Phase steels' manufacturing

\section{Abstract}

Cementite composition in a ferrite-pearlite steel dedicated to the industrial production of Dual-Phase steels has been investigated after hot-rolling and during annealing. By coupling TEM investigations and local field composition modeling using THERMOCALC and DICTRA softwares, its progressive enrichment in manganese is explained.

This enrichment begins during hot-rolling when austenite first decomposes into ferrite and pearlite. Measured enrichments are consistent with a pearlite transformation process governed by two simultaneous local equilibria at the growing fronts between ferrite, cementite and austenite. During subsequent coiling operation and annealing, cementite enrichment in manganese continues. Observed composition profiles can be reproduced considering diffusion simulations with local equilibrium at ferrite/cementite interface. Nevertheless, the known diffusion coefficient of manganese in cementite has been reassessed to explain observed composition gradients.

Both thermodynamic approach of pearlite phase transformation and diffusion simulation must be coupled to follow seamlessly manganese composition gradients in cementite all along the manufacturing process. Such calculation is the key to understand the inheritance effects of hot-rolling on final properties on Dual-Phase steels.

\section{Keywords}

steel, cementite, manganese, pearlite, ferrite

\section{Introduction}

Dual-Phase (DP) steels were developed in the 1980's and have been industrialized since the years 1990-1995 [1, 2]. They are still very widely used in the automotive field where they constitute the majority of the so-called first generation of advanced high strength steels [3]. These steels generally show high levels of Ultimate Tensile Strength (between 600 and $1200 \mathrm{MPa}$ ) and have excellent forming qualities (drawing or bending ability) which makes them suitable for the production of crash 
1 resistance parts [4-6]. The DP microstructures are composed mainly of soft ferrite and hard martensite

2 [1]. The fraction of the latter carbon rich phase is variable (from 5\% to almost 100\%) depending on the

3 targeted grades. The work-hardening rate of DPs is controlled to first order by the fraction of

4 martensite. It is thus of prime importance for a steelmaker to tune finely and control the volume

5 fraction of martensite in their products [7, 8]. The sensitivity of the UTS of DP steels to the martensite

6 fraction is in the range of 10 to $20 \mathrm{MPa} . \%^{-1}$ [9].

8 Thin gage Dual-Phase Ferrite/Martensite steels are mainly produced by intercritical annealing of cold-

9 rolled steel sheets (ie. at temperatures higher than Ac1, in the ferrite/austenite domain) [10-12]. Their

10 final fractions of martensite after quenching and thus their in-use mechanical properties are closely

11 related to their fraction of austenite at the end of annealing. These fractions of austenite are controlled

12 by all the metallurgical mechanisms occurring during reheating and soaking of the cold-strips. Since

13 as-hot rolled bands before cold rolling show mainly ferrite-pearlite microstructures, these mechanisms

14 consist of recovery / recrystallization of deformed ferrite and pearlite, ripening of cementite below

15 Ac1 and austenite transformation above Ac1 [13].

Below Ac1, the recovery processes occur at relatively low temperature and are followed by the recrystallization of ferrite grains. The complexity arises as the recrystallization kinetics is reduced within pearlite structures. The recovery / recrystallization are thus highly coupled phenomena and the coupling depends on the heating rates and the evolutions of pearlite islands (ripening and coarsening). When considering the austenite transformation from these complex states above Ac1, it seems that the local recrystallization state affects the nucleation sites of austenite $[14,15]$. In fully recrystallized states, austenite nucleates preferentially on ferrite grain boundaries in the Mn-rich zones [2, 16-18]. In the case of non-fully recrystallized states, austenite nucleates on carbides in the non-recrystallized ferrite [19]. The resulting topologies of the final microstructures are very different in both scenarios (necklace or banded structures respectively) [2, 14-18].

The evolutions of the chemical compositions and morphologies of cementite, mainly inherited from pearlite domains, affect further austenitization kinetics and thus intercritical annealing conditions. The incubation time for austenite reversion from globular pearlite containing high level of manganese is higher than for non-enriched pearlite [20,21].

The composition in cementite before austenization will be affected by:

- the pearlite transformation conditions: earlier works of Razik et al. on Fe-C-Mn and Fe-C-Cr steels show that pearlite transformation occurs without partition of substitutional elements below $650^{\circ} \mathrm{C}[22,23]$. Nevertheless, experimental growth kinetics was in contradiction with this assumption. More recently, Al-Salman et al. [24], Chance and Ridley [25] and 
Hutchinson [28] obtained experimental results in contradiction with those of Razik et al. as they observed partition of alloying elements between cementite and ferrite down to $550^{\circ} \mathrm{C}$. The fact that partition was detected at so low temperatures in spite of the sluggish diffusivity of substitutional elements suggested for the first time that diffusion occurred not only by volume diffusion, but with an additional contribution of interfacial diffusion, which permits a local equilibrium to be maintained at interfaces. Following the original suggestion of Hillert and Coates [26, 27], Hutchinson in 2004 [28] proposed a complete framework permitting to model this partitioning process. Our results will sustain this latter development.

- the ripening occurring during coiling stage and during reheating prior austenitization in the annealing stage. Miyamoto et al. [34] stated that coarsening obeys to a growth without partition for temperatures inferior to $500^{\circ} \mathrm{C}$, depending on the alloy composition. This observation is supported by Babu [29] and Ghosh and Olson [30] when studying tempering process of martensitic steels. At $500^{\circ} \mathrm{C}$, Song [31] investigated the precipitation of a cementite shell around partially dissolved cementite carbides at $500^{\circ} \mathrm{C}$ in a $100 \mathrm{Cr} 6$ and observed a growth with a weak partition of $\mathrm{Cr}$ and $\mathrm{Mn}$ but with an Mn spike located at the moving interface. These experimental observations suggest that cementite is growing under the regime of negligible partitioning with local equilibrium. At higher temperatures, the authors generally report growth process under local equilibrium with a significant partition of alloying elements (mainly Mn). For instance, Hwang et al. [32] observed the thickening of a cementite lamella at $710^{\circ} \mathrm{C}$ in $1 \mathrm{C}-1.45 \mathrm{Cr}-0.35 \mathrm{Mn}$ wt.\% steel or Philippot et al. [33] in an initial cold-rolled ferrite / martensite microstructure slowly heated up to $700^{\circ} \mathrm{C}$ in a $0.47 \mathrm{C}-2.53 \mathrm{Mn}-0.32 \mathrm{Cr}$ wt. $\%$ steel. In the case of tempered martensitic microstructures, upon coarsening, carbides exhibit first non-partition but are gradually enriched with increasing annealing time as suggested by Miyamoto et al. [34]. Tu et al. [35] explored the concomitant effects of Mn and Si on the spheroidization behavior of severe cold-drawn pearlitic steels, S87B and S87BM (respectively $0.95 \mathrm{C}-1.15 \mathrm{Mn}-0.22 \mathrm{Si}$ wt. $\%$ and $0.93 \mathrm{C}-1.16 \mathrm{Mn}-0.95 \mathrm{Si}$ wt. $\%$ ). The partition of $\mathrm{Mn}$ at $600^{\circ} \mathrm{C}$ is also progressive and the equilibrium composition of cementite is achieved after only $10 \mathrm{~h}$ annealing.

So, enrichment processes in cementite not only depends on the annealing conditions of the ferritecementite microstructure but also on pearlite transformation conditions and heating process.

In this work, we have conducted investigations by TEM (Transmission Electronic Microscopy) in order to measure the chemical compositions at the nanoscale in cementite particles after hot-rolling and during annealing of an industrial steel. These results will be discussed in a second part at the light of thermodynamic calculations using THERMOCALC and kinetics calculations using DICTRA. Following the suggestion of Luo et al. [36], the diffusion coefficient of Mn will be in particular 
1 reassessed to explain the composition gradient measured in cementite particles after coiling operation,

2 i.e. when cooling down the hot-bands after hot-rolling. We will also show that in the studied steel local

3 equilibrium seems to govern interface conditions whatever the temperature range.

4

5 The main originality of our work is to consider the mean composition enrichments and gradients in

6 cementite particles all over the thermomechanical cycle prior to austenitization. The study reveals in

7 particular that a strong manganese enrichment is inherited from pearlitic transformation and coiling

8 treatments, prior to cold-rolling. Nevertheless, slow heating conditions encountered in certain

9 industrial plants during annealing permits to reduce this inheritance effect.

10 Experimental methods and modeling procedures

\section{$11 \quad$ Studied steel}

12 The studied steel is an industrial product which serves for the production of certain DP580 grades. It 13 has been provided by ArcelorMittal in the cold-rolled state. It has undergone a conventional hot14 rolling scheme (reheating of the slabs at about $1200^{\circ} \mathrm{C}$, finish rolling temperature above $900^{\circ} \mathrm{C}$, coiling 15 at $550^{\circ} \mathrm{C}$ after a fast cooling on a run-out-table). After coiling, temperature decreases in the hot-rolled 16 coils with a mean rate of $20^{\circ} \mathrm{C} / \mathrm{h}$ (from $550^{\circ} \mathrm{C}$ down to room temperature). The hot-band has then been 17 cold-rolled (reduction ratio of $60 \%$ ).

18 Table 1 gives the composition of the studied steel. It is a low carbon steel without microalloying elements $(\mathrm{Ti}, \mathrm{Nb}, \mathrm{V})$. The compositions are given in weight fraction and u-fraction. The u-fraction corresponds to the atomic fraction of the considered solute among substitutional species in iron sublattices. It is the natural way to present TEM composition measurements and simulation results, especially when considering interfaces between cementite and ferrite. $U_{B}$ the $u$-fraction of substitutional element B is given by:

$$
\mathrm{U}_{\mathrm{B}}=\frac{\mathrm{X}_{\mathrm{B}}}{\sum \mathrm{X}_{\mathrm{n}}}=\frac{\mathrm{X}_{\mathrm{B}}}{1-\mathrm{X}_{\mathrm{C}}}
$$

$\mathrm{X}_{\mathrm{B}}$ is the atomic fraction of element $\mathrm{B}$ and the sum at denominator is made on all substitutional species in the iron sublattice. The denominator is thus equal to $1-\mathrm{X}_{\mathrm{C}}$, with $\mathrm{X}_{\mathrm{C}}$ the atomic fraction of carbon for this particular case.

\begin{tabular}{|l|l|l|l|l|}
\hline Elements & $\mathrm{C}$ & $\mathrm{Mn}$ & $\mathrm{Si}$ & $\mathrm{Cr}$ \\
\hline weight fraction (\%) & 0.10 & 1.91 & 0.20 & 0.20 \\
\hline u-fraction (\%) & n.a. & 1.94 & 0.41 & 0.21 \\
\hline
\end{tabular}

Table 1: Composition of the studied steel in weight percents and in u-fractions. 
1 The current investigation mainly focuses on manganese as it plays an important role in the

2 austenization process of the studied steel, as highlighted in the introduction. Nonetheless, we will also

3 discuss the evolution of silicon and chromium compositions in carbides.

\section{$4 \quad$ Studied samples}

5 Three samples were investigated by TEM. They correspond to key states of an industrial 6 thermomechanical schedule.

- Sample 1: Sample obtained by heating a sample in the cold-rolled state up to $900^{\circ} \mathrm{C}$ during 30 min, then cooled down at $570^{\circ} \mathrm{C}$ at $30^{\circ} \mathrm{C} \cdot \mathrm{s}^{-1}$ and maintained $30 \mathrm{~s}$ before quenching. The obtained ferrite-pearlite microstructure was thought to be representative of the state before the coiling operation. In fact, our experiments will show that composition of carbides evolve significantly during this long cooling stage. The choice of the transformation temperature $\left(570^{\circ} \mathrm{C}\right)$, above the industrial coiling temperature, is discussed farther.

- Sample 2: Sample in the as-received state, thus taken from the cold-rolled band without additional heat-treatment.

- Sample 3: Sample obtained by heating a sample in the cold-rolled state up to $700^{\circ} \mathrm{C}$ at a constant heating rate $\left(3^{\circ} \mathrm{C} \cdot \mathrm{s}^{-1}\right)$ and quenched. The obtained ferrite-pearlite microstructure was thought to be representative of the state just before the intercritical range $\left(\mathrm{Ac} 1=740^{\circ} \mathrm{C}\right)$ and thus before austenite phase transformation.

Heat treatments were carried out with a homemade Rapid Cycle Dilatometer. The furnace is composed of four light bulbs of $1500 \mathrm{~W}$ and temperatures are measured by welded thermocouples. Quenching steps are achieved by cold helium injections.

\section{SEM (Scanning Electronic Microscopy) sample preparation and configurations}

Samples have been coated with epoxy resin (sagittal cut) and polished with silicate grid paper down to $1 \mu \mathrm{m}$ and finished using a colloidal silica suspension solution. Before etching, an ultra-sonic cleaning bath in warm methanol $(\sim 30 \mathrm{~min})$ permits to remove the fine colloidal silica particles and to avoid pollution of the samples. The samples are then etched with a Picral solution at $2 \%$. Observations have been conducted on Phillips FEG-SEM XL30 microscope in Secondary Eelectron mode. Micrographs have been taken at quarter thickness in order to avoid skin effects and a possible central macrosegregated band.

\section{TEM (Transmission Electronic Microscopy) sample preparation and} configurations

Specimens for TEM investigations were ground parallel to the initial faces of the flat products down to a thickness of about $60 \mu \mathrm{m}$ using grinding papers. Both sides of specimens were polished to remove possible decarburized layers, trying however to avoid the central segregation. After that, specimens 
1 were manually punched to obtain $3 \mathrm{~mm}$ diameter cylindrical samples. Finally, foils were drilled by 2 electropolishing using perchloric-acetic acid solutions. The electrolytic solution was used at $18^{\circ} \mathrm{C}$ with 3 a tension of $30 \mathrm{~V}$. Appropriate electropolishing parameters were sought to remove ferritic matrix while 4 preserving cementite carbides. Before observations, foils were cleaned using a Precision Ion Polishing 5 System (Gatan 691 PIPS).

6

7 JEOL TEM microscope was operated at $200 \mathrm{kV}$ (ARM FEG). Composition measurements were 8 performed with a BRUKER XFlash EDXS Silicon Drift Detector with a chemical resolution of 127 $9 \mathrm{eV}$ and a collector plate of $30 \mathrm{~mm}^{2}$. The measurements presented in the following have been obtained with a probe size of $1 \mathrm{~nm}$ (1000 times finer than a conventional Castaing microprobe). Accounting for the thickness of the foil and contrary to SEM, there is no enlargement of the excitation volumes within the sample. The analyzed volume is thus limited to the probe size diameter.

EDXS measurements are by nature punctual, but repeating the measurements along lines and columns permits to reconstruct composition profiles or maps. A minimum spatial step of $5 \mathrm{~nm}$ was chosen to provide suitable compromise between spatial resolution and X-ray counts, in order to obtain statistically meaningful results in a reasonable period of time.

Detection of light chemical species like carbon is not possible by EDXS method because of the energy resolution. For this reason, it has been carried out only for major substitutional elements for Fe like $\mathrm{Mn}, \mathrm{Cr}$ and $\mathrm{Si}$. The measured concentrations are given by the Desktop Spectrum Analyzer (DTSA) in relative atomic site-fraction. As carbon is not considered in the balance, the measurements correspond to the $\mathrm{u}$-fractions for each element. The typical relative error for measured substitutional concentrations was calculated using standard statistical techniques and does not exceed 5\% (relative value). An Electron Energy Loss Spectroscopy (EELS) detector has also been used to estimate the local thickness of the foil. For each studied state, about 5 particles have been studied in details (composition profiles). These particles were located in pearlite islands (not isolated at a ferrite grain boundary) to obtain a possible correlation with our thermodynamic prediction. However, it is not possible to tell with certainty that they are located in a microsegregated band.

The thermodynamic calculations were done with THERMOCALC and DICTRA (version 


\section{Experiments}

2 In this section, we will first describe the ferrite-pearlite microstructures in the as-received sample 3 (sample 2) and after heating up to $700^{\circ} \mathrm{C}$ (sample 3) observed by SEM. Sample 1 shows a 4 microstructure which is very similar to sample 2 except the effect of the cold-rolling strain. After these

5 SEM observations at the micro scale, our local composition measurements in cementite by TEM will 6 be presented.

\section{$7 \quad$ SEM observations of the as-received and annealed states (samples 2 and 3)}

8 Figure 1a shows a typical SEM micrograph of the studied steel in the as-cold-rolled state before 9 annealing. The microstructure after hot-rolling and cold-rolling is made of elongated ferrite grains 10 (dark contrast) with a typical size of $10 \mu \mathrm{m}$ and of cementite carbides (bright contrast). Cementite is 11 mainly located in pearlitic lamellar colonies but few isolated intergranular carbides can also be 12 observed (about 0.44 particles. $\mu \mathrm{m}^{-2}$ ). A composition mapping using a Castaing microprobe (not 13 presented here) reveals microsegregated bands inherited from continuous casting. These bands are 14 approximatively $30 \mu \mathrm{m}$ wide and show $\mathrm{Mn}$ u-fraction fluctuations between 1.78 and $2.10 \%$. 15 Microsegregations of silicon and chromium are negligible on the contrary. These composition 16 fluctuations play a role on the formation of the pearlite as they modify locally the interface conditions 17 between austenite, ferrite and cementite during the transformation. Pearlitic islands are thus more often 18 located in Mn microsegregated bands but it is not systematic. 

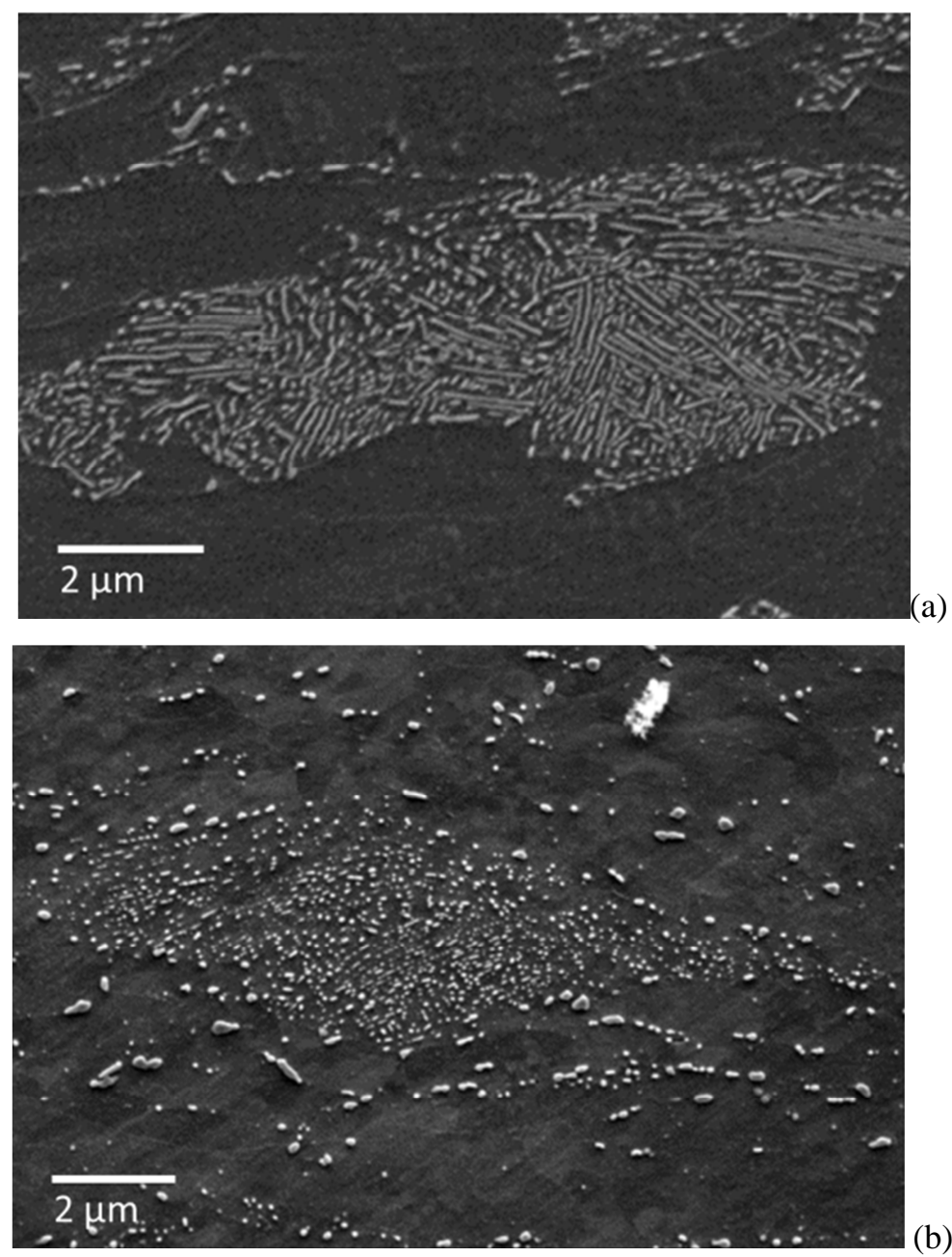

Figure 1: SEM in Secondary Electron mode of studied microstructures after Picral etching (a) sample 2 and (b) sample 3 respectively.

6 Figure $1 \mathrm{~b}$ shows the microstructure obtained after slow heating at $700^{\circ} \mathrm{C}$. The pearlite lamellae have 7 undergone a severe ripening consisting mainly of a fragmentation process [37]. The isolated carbides 8 are slightly more numerous (about 2.6 particles. $\mu \mathrm{m}^{-2}$ ) and have grown up (higher mean diameter 9 compared to sample 2).

\section{TEM observations and local compositions measurements}

\section{After pearlite transformation (sample 1)}

12 Figure 2 shows a representative TEM BF (Bright Field) micrograph of the microstructure just after 13 transformation at about $570^{\circ} \mathrm{C}$ in hot-rolling process. As observed in SEM in sample 2, it consists 14 mainly of pearlitic lamellar colonies (cementite in dark contrast) surrounded by large pro-eutectoid 15 ferrite grains (large bright areas) containing isolated cementite carbides at grain boundaries. 


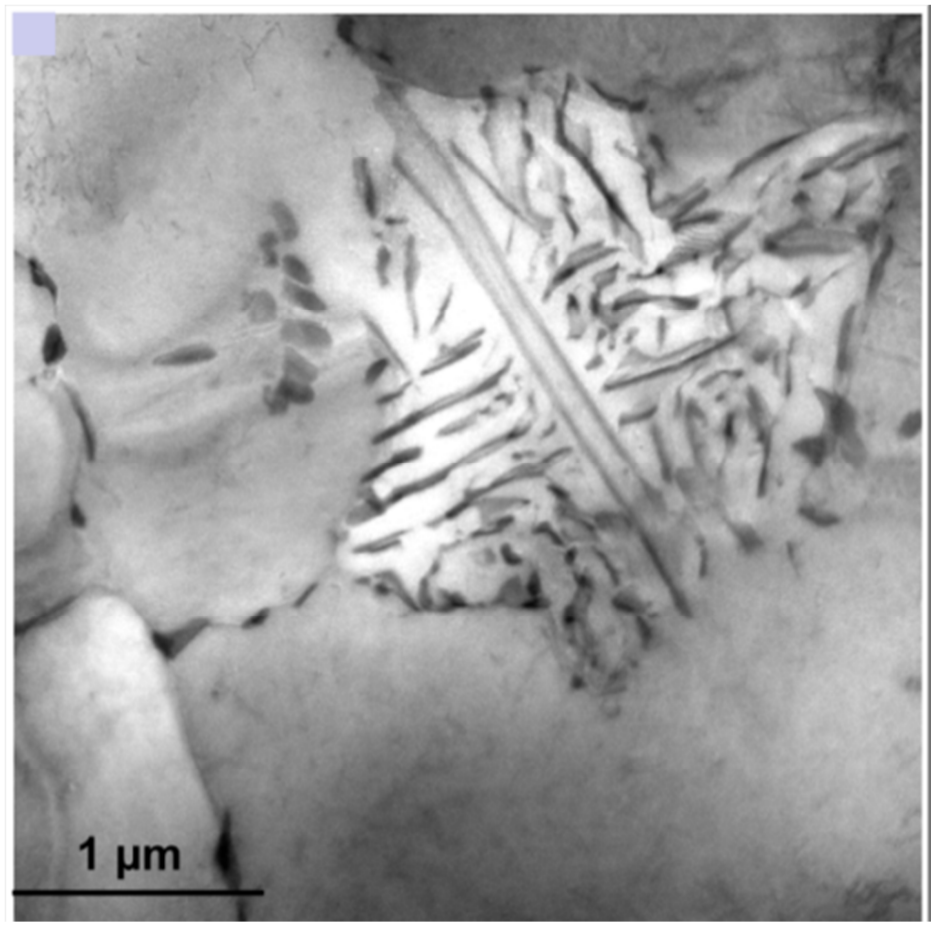

Figure 2: TEM BF (Bright Field) of a lamellar pearlite island formed at $570^{\circ} \mathrm{C}$. The latter is surrounded by large pro-eutectoid ferrite grains. Intergranular carbides are found along the grain boundaries.

To perform reliable EDXS measurements, the height of studied cementite lamella or particle must exceed the thickness of thin foil. In this manner, electronic beam surely goes through cementite only. If not, the measurement can be affected by the presence of ferrite above or below the cementite particle and thus leads to underestimate manganese enrichment in cementite. In the following, such experimental artefact will be systematically avoided.

Nevertheless, it is not possible to guaranty that the interfaces of cementite lamellae are always strictly parallel to the incident beam. Measurements close to the interfaces must thus be considered with care as the slightly tilted lamella can also hide the presence of ferrite under the beam. This is the reason why on the composition profiles presented below we will systematically highlight the measurement points that can be affected by such tilting issue.

Figure 3a shows an example of composition measurement inside a cementite lamella. The etching depth difference between the lamella and its matrix is about $25 \mathrm{~nm}$, according to the EELS signal. Investigated lamella appears in dark contrast and the surrounding ferrite in bright. An EDXS profile was obtained thanks to 10 aligned punctual measurements (10 $\mathrm{nm}$ step size) and is represented in Figure 3b. 

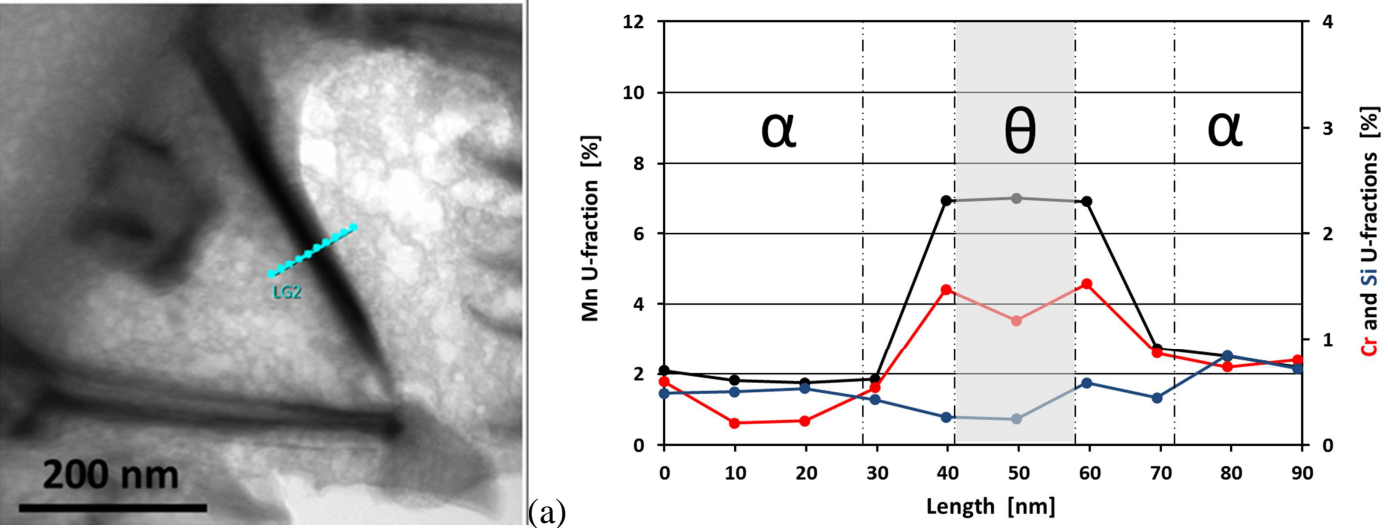

(b)

Figure 3: (a) TEM BF micrograph of cementite lamella (dark contrast) emerging from the thin foil and its surrounding matrix (bright contrast) in sample 1. The aligned blue points correspond to the positions of EDXS measurements to establish a composition profile across the carbide and its surrounding matrix. (b) Mn (black), $\mathrm{Cr}$ (red) and Si (blue) u-fraction profiles. The areas bounded by the dashed lines indicate spots where the TEM beam could cross simultaneously ferrite and cementite at interface due to a possible tilting issue.

The composition profile within the cementite lamella is flat and reveals a significant enrichment up to $\mathrm{U}_{\mathrm{Mn}}=7 \%$. The Mn composition in the matrix is uniform and similar to the nominal one $\left(\mathrm{U}_{\mathrm{Mn}}=1.94\right.$ $\%)$ meaning that the observed pearlite aggregate is not located inside an Mn microsegregated region. The $\mathrm{Cr}$ concentration in the matrix is close to the nominal one while an enrichment up to $\mathrm{U}_{\mathrm{Cr}}=1.5 \%$ is observed inside the lamella. On the contrary to $\mathrm{Mn}$ and $\mathrm{Cr}$, Si shows a constant profile through the matrix and the lamella, which corresponds to the nominal composition $\left(\mathrm{U}_{\mathrm{Si}}=0.4 \%\right)$.

Our systematic investigations on other adequate configurations confirm systematically a Mn enrichment in cementite between $6 \%$ and $8 \%$. This result confirms that pearlitic transformation at $570^{\circ} \mathrm{C}$ in studied steels occurs with a partition of $\mathrm{Mn}$ and $\mathrm{Cr}$, in accordance with the works of $\mathrm{Al}-$ Salman et al. [24], Chance and Ridley [25] or Hutchinson [28].

\section{As-received state (sample 2)}

As in sample 1, different cementite particles have been studied by TEM with the experimental limitations discussed above. Figure 4a shows for instance a fragment of cementite lamella with a suitable thickness (20 $\mathrm{nm}$ thicker than the foil). Therefore, the carbide (clear contrast) arises surely from the matrix. The concentration measurements measured along the blue line are reported in Figure $4 \mathrm{~b}$. 

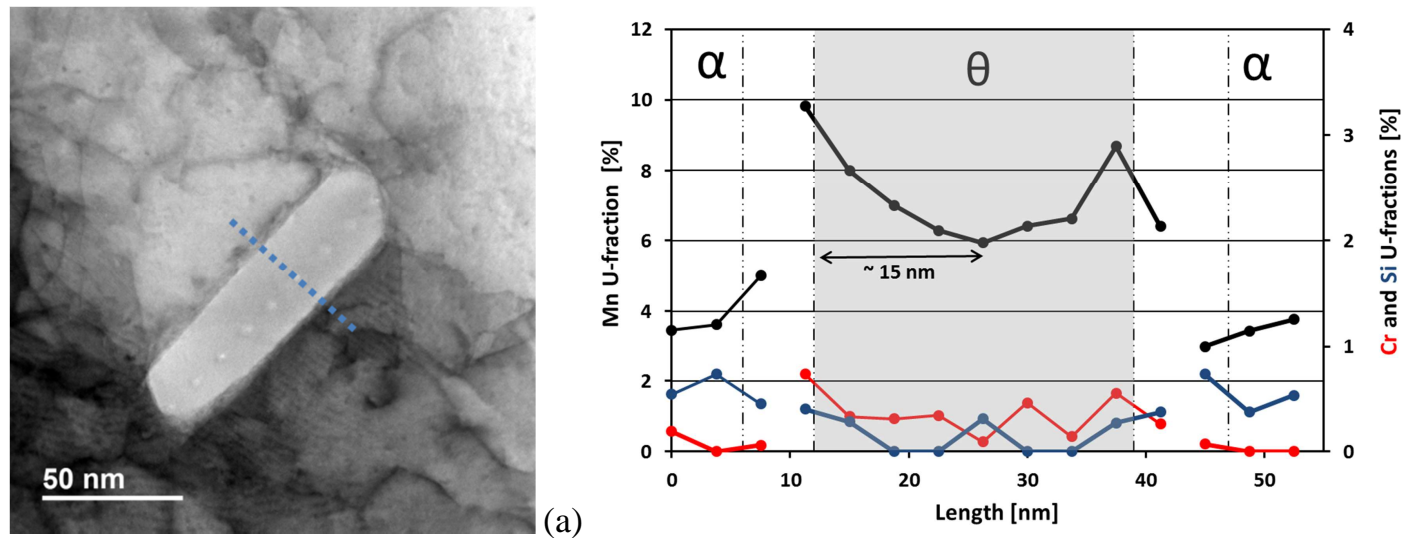

(b)

Figure 4: (a) TEM BF micrograph of cementite lamella (object with the brightest contrast) emerging from the thin foil and its surrounding matrix in sample 1. The aligned blue points (step size $=5 \mathrm{~nm}$ ) correspond to the positions of EDXS measurements to establish a composition profile across the carbide and its surrounding matrix. (b) Mn (black), $\mathrm{Cr}$ (red) and Si (blue) u-fraction profiles. The areas bounded by the dashed lines indicate spots where the TEM beam could cross simultaneously ferrite and cementite at interface due to a possible tilting issue.

Mn concentration in ferrite in the studied field is about $\mathrm{U}_{\mathrm{Mn}}=4 \%$. This value is significantly higher than the nominal one, meaning that this cementite particle is located in a Mn microsegregated band. In cementite, a U-shaped concentration profile of $\mathrm{Mn}$ is observed bringing to light a significant $\mathrm{Mn}$ concentration gradient at interface, extended over about $15 \mathrm{~nm}$. This profile reaches a maximum $\mathrm{Mn}$ concentration in cementite near $\mathrm{U}_{\mathrm{Mn}}=10 \%$ at interface cementite / ferrite, while a slight depletion is visible in surrounding matrix (only on the right side). A minimum value of $\mathrm{U}_{\mathrm{Mn}}=6 \%$ is observed in the middle of the $\mathrm{U}$-shaped profile. $\mathrm{Cr}$ concentration in cementite is also not uniform and shows an average value of $0.5 \%$, which is two times higher than the nominal composition. Si seems to be rejected from cementite into the surrounding ferrite (two times higher than the nominal value) as expected from the observations of many authors [34, 38, 39]. For these two last elements, their nominal contents and their local fluctuations prevent from determining convincing gradients from experiments. Hence, in the following, we have considered as useless to simulate the corresponding composition profiles and compare them with our experimental measurements.

Figure 5a shows a cementite lamella undergoing a ripening process as its extremity is rounded. This bulging process, as described by Tian and Kraft [40], is made possible by the coiling operation after hot rolling which corresponds in fact to a long cooling stage after the pearlitic transformation. As for the previous studied cases, the compositions measured along the line in Figure 5a are plotted in Figure $5 b$ with a step size of $17 \mathrm{~nm}$. 

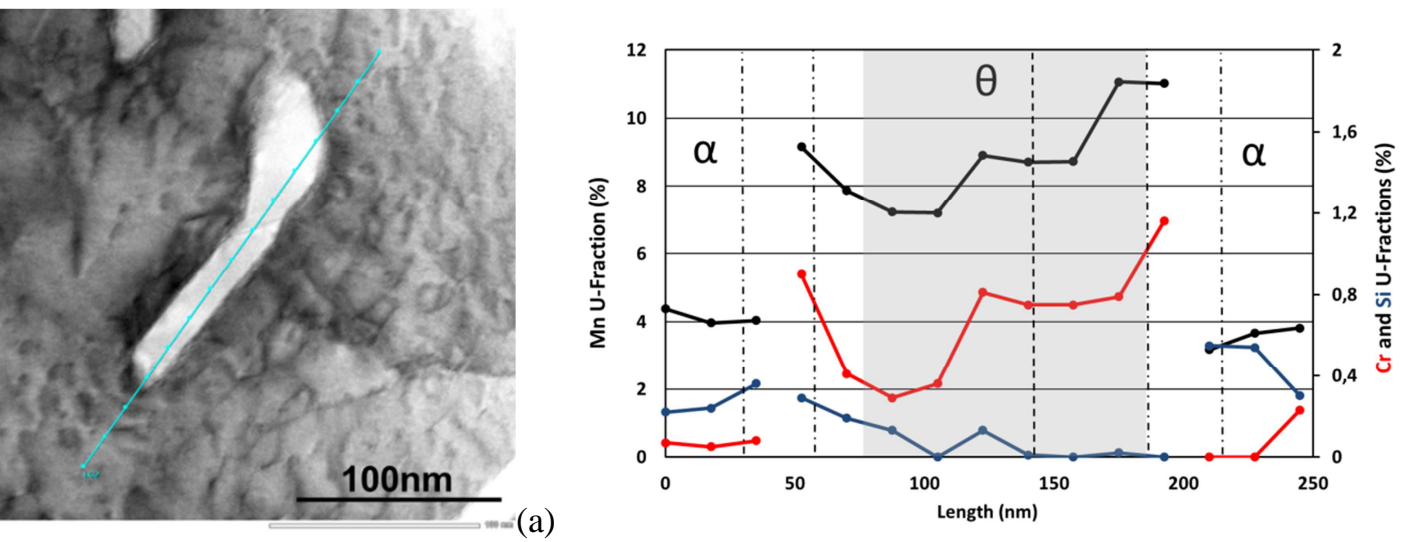

(b)

2 Figure 5: (a) TEM BF micrograph of second cementite lamella (dark contrast) emerging from the thin foil and its surrounding matrix (bright contrast) in sample 1. The aligned blue points (step size $=17$ $n m)$ correspond to the positions of EDXS measurements to establish a composition profile across the carbide and its surrounding matrix. (b) Mn (black), $\mathrm{Cr}$ (red) and $\mathrm{Si}$ (blue) u-fraction profiles. The dashed line indicates the position of the sub-grain separating the straight and the bulged part of the particle. The areas bounded by the dot-dashed lines indicate spots where the TEM beam could cross simultaneously ferrite and cementite at interface due to a possible tilting issue.

The composition profiles also reveal U-shaped concentration profiles of $\mathrm{Mn}$ and $\mathrm{Cr}$ in the straight part of the particle, with a Mn concentration at interface similar to the previous case (Figure 4), close to $10 \%$, but with slightly more extended gradients (about 2 step sizes). At the deepest point of the Ushaped profile, the $\mathrm{u}$-fraction of $\mathrm{Mn}$ is about $7 \%$ as in the preceding case. The $\mathrm{u}$-fraction of $\mathrm{Cr}$ is about $1 \%$ at the ferrite / cementite interface and about $0.4 \%$ approximatively at the center of the lamella. $\mathrm{Si}$ is rejected into the ferritic matrix. In the rounded bulb, a significant enrichment in $\mathrm{Mn}$ and $\mathrm{Cr}$ is also measured. $\mathrm{Mn}$ and $\mathrm{Cr}$ concentrations reach $11 \%$ and $1.3 \%$ at the interface. Therefore, partitioning of substitutional elements is even higher in carbide undergoing a ripening process.

When studying other precipitates, we measured concentrations between 6 and 12\%. We thus confirmed that $\mathrm{Mn}$ and $\mathrm{Cr}$ concentrations in cementite continue to increase during coiling, i.e. after pearlite transformation but at temperature lower than $550^{\circ} \mathrm{C}$. Nevertheless, their repartitions are not uniform. U-shaped composition profiles are observed whose gradients are extended over few tens of $\mathrm{nm}$. At the interface, the $\mathrm{u}$-fractions of $\mathrm{Mn}$ are close to $12 \%$ whereas in the middle of particles, local compositions remain similar to those observed in sample 1. During this long cooling stage $\left(20^{\circ} \mathrm{C} \cdot \mathrm{h}^{-1}\right)$, cementite lamellae undergo also a ripening process (fragmentation and bulging) but this process is limited as pearlitic structures are still mainly lamellar, as shown in Figure 1a. 
Interrupted annealing at $700^{\circ} \mathrm{C}$ (sample 3)

2 Next observations have been made on sample 3 after hot-rolling and cold-rolling heated slowly at

$3 \quad 3^{\circ} \mathrm{C} \cdot \mathrm{s}^{-1}$ up to $700^{\circ} \mathrm{C}$ and quenched. As observed in Figure $1 \mathrm{~b}$ by SEM, our TEM observations confirm

4 that lamellar pearlitic microstructures have undergone a severe ripening. Cementite lamellae are

5 fragmented and remnants are round-shaped.

6 The transversal concentration profile in a lamellar fragment has been measured and is represented in

7 Figure 6 . The studied carbide is suspended into vacuum by one extremity avoiding a possible dilution 8 effect.

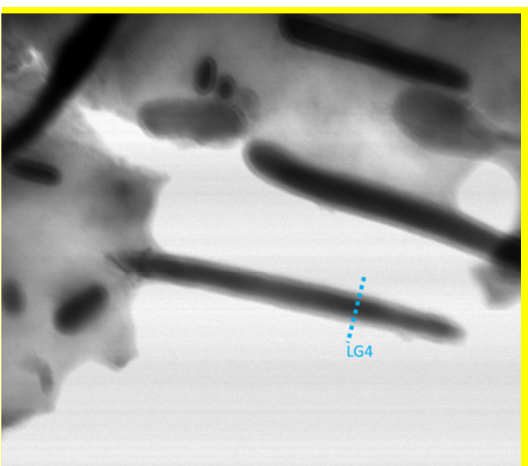

$100 \mathrm{~nm}$

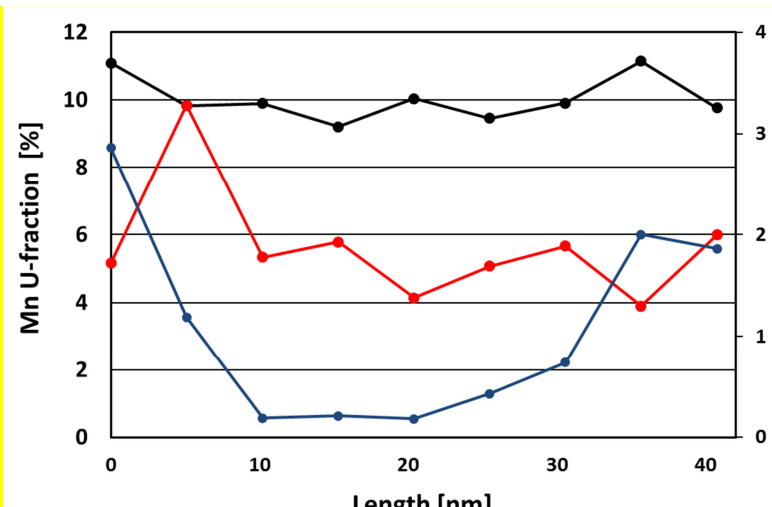

(a)

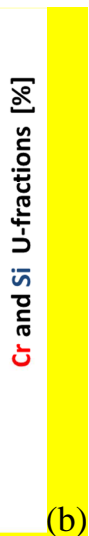

(b)

Figure 6: (a) TEM BF micrograph of cementite lamella (dark contrast) suspended into vacuum by one extremity emerging in sample 3. The aligned blue points ( $\mathrm{step}$ size $=5 \mathrm{~nm}$ ) correspond to the positions of EDXS measurements to establish a composition profile across the carbide and its surrounding matrix. (b) Corresponding Mn (black), $\mathrm{Cr}$ (red) and Si (blue) u-fraction profiles.

The Mn composition in the matrix is about 3\% meaning that the lamella is located in a microsegregated band. In the studied particle, the $\mathrm{Mn}$ and $\mathrm{Cr}$ composition profile are almost flat (the residual gradient is about $2 \%$ over $20 \mathrm{~nm}$ ). The average $\mathrm{u}$-fractions of manganese and chromium are about $10 \%$ and $2 \%$ respectively. $\mathrm{Mn}$ and $\mathrm{Cr}$ enrichment are thus higher than in sample 2 . On the contrary, Si seems to have been rejected again from the particle.

\section{Intermediate conclusion on cementite enrichment in manganese}

To conclude, the experiments reveal that pearlite transformation at $570^{\circ} \mathrm{C}$ in the studied steel (sample 1) occurred with a noticeable partition of $\mathrm{Mn}$ (u-fraction of about 7\%) into cementite. In contrast, $\mathrm{Si}$ concentration remains constant through cementite and matrix and corresponds to the nominal values. During coiling, i.e. the slow cooling down to room temperature $\left(20^{\circ} \mathrm{C}^{-1} \mathrm{~h}^{-1}\right.$, sample 2$)$, the $\mathrm{Mn}$ bulk composition of cementite does not evolve, but strong gradients, about 10-30 nm wide are found at interfaces with interfacial concentration at about $11 \%$. The initial partition due to the transformation condition is thus reinforced during coiling by diffusion but observed composition gradients is the 
1 proof that cementite is far from being at equilibrium in the as-rolled state. This enrichment prior 2 annealing is often neglected in most of the studies dedicated to the annealing of ferrite-cementite 3 microstructure. After heating at $700^{\circ} \mathrm{C}$ (sample 3), Mn seems more homogenously distributed in 4 cementite with an average composition of about $10 \%$. In the following part, thermo-chemical and 5 diffusion analysis will be thus performed to interpret the above EDXS measurements.

\section{Discussion and modeling}

7 This discussion will be divided into two parts. In the first part, the combined findings of Hillert and 8 Pandit [26,47] are rationalized in order to predict thermodynamically the composition of the pearlite's 9 constituents and thus explain the measured compositions inside cementite in the as-transformed state 10 (Sample 1). To our knowledge, we are the first to bring experimental evidence of the validity of such 11 a thermodynamical prediction for hypoeutectoid steels in anisothermal condition. In the second part, 12 the composition evolution in cementite during coiling and annealing will be modeled with DICTRA 13 software, in order to explain composition gradients in as-received and annealed states (Samples 2 and 14 3, respectively). This work has required reassessing Mn diffusion coefficient in the commercial 15 MOBFE2 database. Coupling the model for phase transformation and diffusion calculations thus 16 permits to predict the local Mn composition field in cementite particles all along steel manufacturing. Manganese partition during pearlite transformation

Prior pro-eutectoid transformation and criterion for pearlite transformation start

The ferrite-pearlite microstructure obtained after hot-rolling is the product of a two-step decomposition of austenite. The pro-eutectoid ferrite transformation occurs first in recrystallized austenite. The pro-eutectoid transformation temperature in the studied steel has been measured using a dilatometer around $685^{\circ} \mathrm{C}$ for the studied cooling condition $\left(20^{\circ} \mathrm{C} . \mathrm{s}^{-1}\right)$ (neglecting possible interactions with austenite deformation). This temperature is far below the NPLE (negligible partitioning local equilibrium)/PE (Para Equilibrium) transition temperature determined by Zurob around $825^{\circ} \mathrm{C}$ [41, 42] (for an alloy Fe-0.57C-0.94Mn). Ferrite transformation in the studied steel occurs thus under NPLE conditions, in accordance also with the work of Chen et al. [43]. It thus means that the substitutional solute composition of untransformed austenite remains constant during ferritic pro-eutectoid transformation. Only its carbon concentration increases progressively. It is generally admitted that the pearlitic transformation then occurs when the carbon concentration is high enough, i.e. when the local composition in untransformed austenite reaches the extrapolated Acm boundary below the eutectoid point. This criterion is called Hultgren criterion. condition in industrial conditions. 
1 TACSI software is a simulation tool for intelligent manufacturing able to simulate the phase 2 transformations occurring during hot-rolling of conventional high strength steels, considering complex

3 thermomechanical schedules. The predicted microstructures (phases, size, precipitation state...) then

4 serve to predict the mechanical properties of the steels using micromechanical approaches. When

5 linked to sensors on industrial plants, TACSI is used to drive the industrial production and is able to

6 predict the local mechanical properties on coils. The model is thus calibrated on large industrial and

7 laboratory databases. The module used to calculate the ferrite/pearlite transformations from austenite

8 (deformed or not) has been extensively described in previous papers [44, 45].

9 In this model, the Classical Nucleation Theory (CNT) developed by Aaronson et al. [51-54] is applied.

10 Ferrite growth is modeled by a mixed-mode approach. Pearlite transformation is triggered according to

11 a modified Hultgren criterion calibrated on a large database. For studied steels and cooling conditions,

12 it has been established that pearlite transformation starts at $570^{\circ} \mathrm{C}$. For studied steels and cooling

13 conditions, it has been established with the TACSI software that pearlite transformation starts at $14570^{\circ} \mathrm{C}$.

This value has been confirmed by analyzing the interlamellar spacing in the as-received state (cf. Figure 1a). The mean interlamellar spacing, measured in cold-rolled pearlite by the planar intercept method is $48 \mathrm{~nm}$. The stereological correction proposed by Ridley [49] for pearlite was applied. The true interlamellar spacing before cold-rolling is thus calculated using equation (2) [57]:

$$
S_{\varepsilon}=S_{0} \cdot \exp \left(-\frac{\varepsilon}{2}\right)
$$

where $S_{\varepsilon}$ is the interlamellar spacing after cold-rolling. $\varepsilon$ is the plastic equivalent deformation by rolling and can be calculated with Equation (3) [58]:

$$
\varepsilon=\frac{2}{\sqrt{3}} \cdot \ln \left(\frac{1}{1-R}\right)
$$

where $\mathrm{R}$ is the cold rolling ratio.

The empirical law of Marder [46] gives the interlamellar spacing as function of the difference between $\mathrm{A}_{\mathrm{e} 1}$ and the transformation temperature for continuous cooling according to the equation (4):

$$
S_{O}=\frac{8020}{\Delta T}
$$

where $S_{0}$ is the interlamellar spacing in $\mu \mathrm{m}$ and $\Delta \mathrm{T}$ the temperature shift with respect to $\mathrm{A}_{\mathrm{e} 1}$ in ${ }^{\circ} \mathrm{C}$.

The upper Ae1 temperature of the studied steel is $682^{\circ} \mathrm{C}$ according to THERMOCALC. Inverting Marder's relationship [46] gives then a transformation temperature of $585^{\circ} \mathrm{C}$, very close to the predicted one by TACSI. 
At $570^{\circ} \mathrm{C}$ (from TACSI), the empirical Acm formula of Lee [55] predicts a carbon concentration in austenite of $0.39 \%$ wt. The lever rule then gives a volume fraction of pearlite of $25 \%$, which is close to our experimental observations ( $16 \%$ considering only well delimited pearlite islands). As qualitative explanation, the difference between measured and expected pearlite fraction is given by the presence of the isolated cementite carbides which represent the carbon missing to achieve the complete pearlite volume fraction. Lee et al. [56] elegantly depicted the formation of such particles which occurs concomitantly to the growth of the pro-eutectoïd ferrite grains.

Finally, it should be highlighted that an error of $+/-10^{\circ} \mathrm{C}$ on the transformation temperature leads to a difference of $2 \%$ on the pearlite fraction in the studied range (around $570{ }^{\circ} \mathrm{C}$ ) using the empirical. Thus, a high degree of precision on this transformation temperature is not necessary to set the proposed simulation chain of the paper.

\section{Interface conditions for pearlite transformation}

The pearlite transformation from carbon rich austenite involves two phases growing in a cooperative manner and sharing a common front with the remaining austenite. Since the substitutional species diffuse far slower than carbon, the growth mode of pearlite could induce or not a partition of alloying elements between ferrite and cementite.

Early studies of Razik et al. on Fe-C-Mn and Fe-C-Cr [22, 23] steels announce that below about $650^{\circ} \mathrm{C}$, no partition is observed. However, the comparisons of experimental growth kinetics with those calculated from the former assumption are in complete disagreement. Al-Salman et al. [24] observed manganese partitioning in $\mathrm{Fe}-\mathrm{C}-\mathrm{Mn}-\mathrm{Cr}$ steel at temperatures down to $600^{\circ} \mathrm{C}$, but were unable to identity a threshold temperature between growth modes with or without partition. Chance and Ridley [25] extended this finding by observing partition for temperatures as low as $550^{\circ} \mathrm{C}$. The fact that partition was detected at such low temperatures despite of the weak diffusivity of substitutional elements suggested for the first time that diffusion occurred not only by bulk diffusion. An interfacial diffusion must in fact be considered to maintain a local equilibrium at the interface. More recently, Hutchinson [28] reported again a manganese partitioning in strongly alloyed steels (up to $\mathrm{U}_{\mathrm{Mn}}=6.8 \%$ at $625^{\circ} \mathrm{C}$ ). The experimental results to date from the literature lead to conclude that substitutional elements do partition at any temperature where pearlite is known to grow [41]. Hillert [26] developed an interesting framework to estimate the composition of growing cementite and ferrite in ternary alloys, successfully applied by Hutchinson et al. [28]. The approach is based on two important assumptions:

(1) Local Equilibrium (LE) conditions prevail at both $\gamma / \alpha$ and $\gamma / \theta$ interfaces

(2) Carbon diffuses much faster than Mn. Therefore, the carbon activity is assumed uniform in the vicinity of the growing fronts as well as in the bulk austenite.

Consistently, it involves that a single carbon iso-activity line passes through the bulk composition and intercepts both $\gamma / \alpha+\gamma$ and $\gamma+\theta / \theta$ phase boundaries. In the following, thermodynamic calculations 
only take into account $\mathrm{Mn}$. Indeed, accounting of $\mathrm{Cr}$ or Si did not modify significantly the simulation results. Moreover, as explained above, experimental measurements regarding $\mathrm{Cr}$ and $\mathrm{Mn}$ are not relevant enough to be compared to simulations (only mean trends can be observed). Figure 7 shows the carbon iso-activity line of the austenite bulk composition in an isothermal section of the Fe-C-Mn ternary diagram at $570^{\circ} \mathrm{C}$ calculated with THERMOCALC. This black dotted-dashed line passes through the blue dot representing the initial bulk composition. The red and black continuous lines represent respectively the $\alpha+\gamma$ and $\gamma+\theta$ two-phase field boundaries. These lines were mapped 8

Ternary diagram Fe-C-Mn at $570^{\circ} \mathrm{C}$

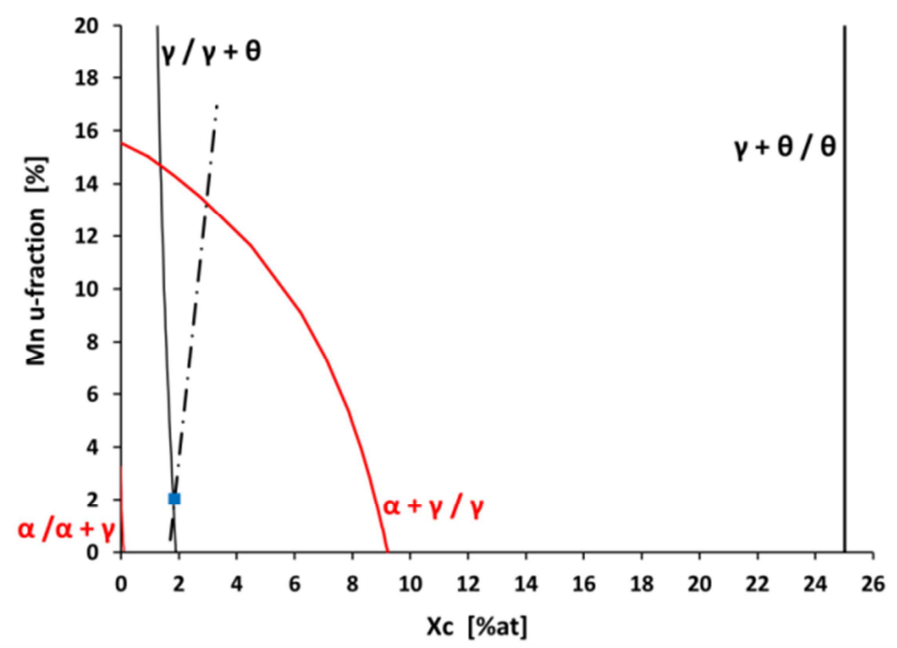

Figure 7: Isothermal section of the $\mathrm{Fe}-\mathrm{C}$-Mn diagram at $570^{\circ} \mathrm{C}$. The dotted-dashed line represents the carbon iso-activity determined from the austenite bulk composition. The two domains delimited by the red and black boundaries represent respectively the $\alpha+\gamma$ and $\theta+\gamma$ two-phase fields.

The interception of the carbon iso-activity line with the phase boundaries indicates the compositions prevailing at the $\gamma$ side at the $\gamma / \alpha$ and the $\gamma / \theta$ interfaces respectively. The corresponding LE tie-lines can then be calculated to deduce the compositions of the growing ferrite and cementite.

For the current study, THERMOCALC calculations give in austenite $\mathrm{U}_{\mathrm{Mn}}=13.3 \%$ at the $\alpha / \gamma$ interface and $\mathrm{U}_{\mathrm{Mn}}=1.6 \%$ at the $\theta / \gamma$ interface. The two corresponding configurations are represented separately in Figures $8 \mathrm{a}$ and $8 \mathrm{~b}$ (for $\theta$ and $\alpha$ respectively). In both cases, the dotted-dashed line still represents the carbon iso-activity line and the dashed lines represent the operative tie-lines at $\theta / \gamma$ and $\alpha / \gamma$ interface respectively. For the studied configuration, the Mn compositions predicted in cementite and ferrite are $\mathrm{U}_{\mathrm{Mn}}=6.05$ and $2.33 \%$ respectively. 


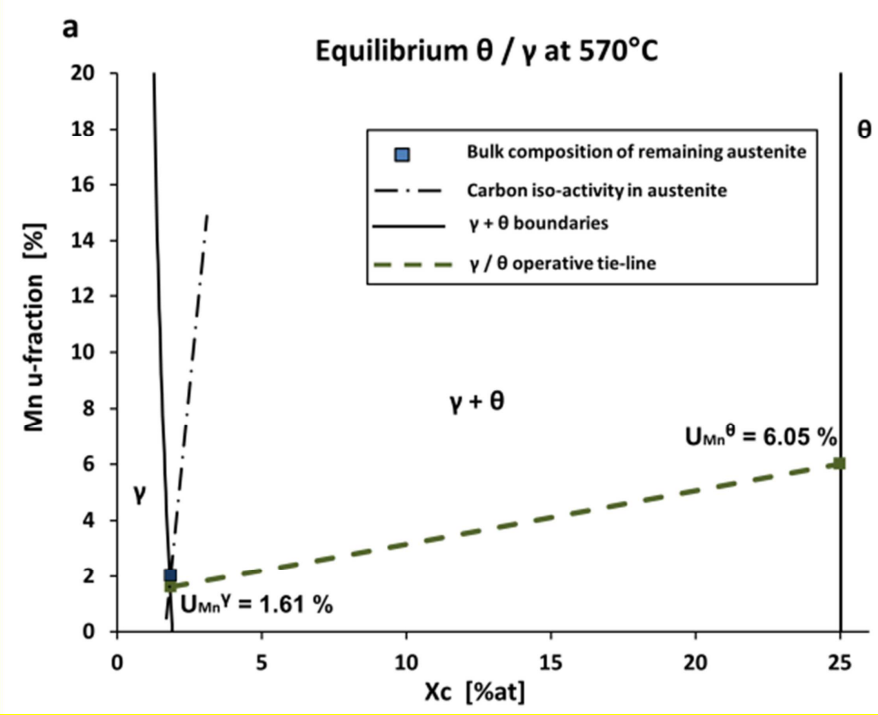

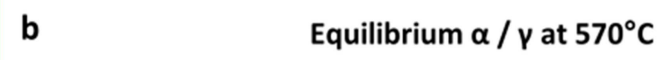

b

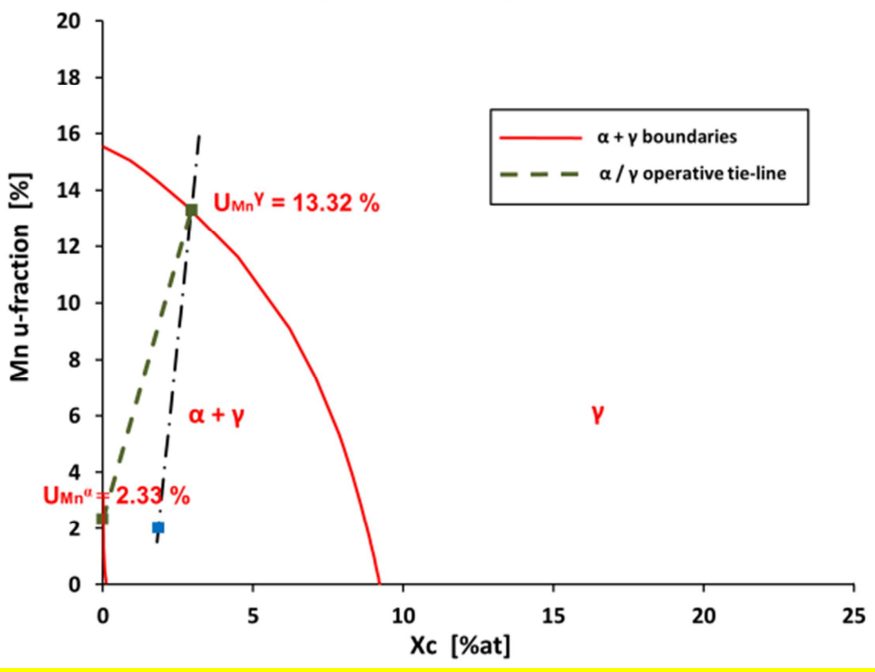

(b)

Figure 8: Isothermal section of $\mathrm{Fe}-\mathrm{C}$-Mn ternary diagram for $(\mathrm{a}) \theta / \gamma$ and $(b) \alpha / \gamma$ metastable equilibrium. The dotted dashed line is the carbon iso-activity line that is used to find the composition of austenite, cementite and ferrite at the $\theta / \gamma$ and $\alpha / \gamma$ interfaces. It enables the calculation of the effective tie-lines relative to each equilibrium and thus to deduce the Mn compositions of the growing phases.

The predicted Mn compositions of cementite and ferrite (respectively $\mathrm{U}_{\mathrm{Mn}}=6.05$ and $2.33 \%$ ) are in excellent agreement with TEM measurements of sample $1\left(\mathrm{U}_{\mathrm{Mn}}=6.6\right.$ and $\left.1.90 \%\right)$, supporting the assumption of a partitioned growth of pearlite with local specific equilibria at $\gamma / \alpha$ and $\gamma / \theta$ interfaces. One emphasizes that the composition in cementite would be significantly different if an equilibrium $\alpha$ / $\theta$ had been considered at $570^{\circ} \mathrm{C}\left(\mathrm{U}_{\mathrm{Mn}}{ }^{\theta}=19 \%\right)$. 
1 However, the previous thermodynamic prediction does not satisfy a priori the Mn solute molar 2 balance, such that:

$$
f_{M}^{\theta} \cdot X_{M n}^{\theta}+f_{M}^{\alpha} \cdot X_{M n}^{\alpha}=X_{M n}^{0}
$$

4 where $\mathrm{X}_{\mathrm{Mn}}^{0}$ is the nominal atomic Mn composition of $\gamma \cdot \mathrm{X}_{\mathrm{Mn}}^{\theta}$ and $\mathrm{X}_{\mathrm{Mn}}^{\alpha}$ are the atomic Mn compositions 5 of cementite and ferrite respectively, determinated with the latter approach. $\mathrm{f}_{\mathrm{M}}^{\theta}, \mathrm{f}_{\mathrm{M}}^{\alpha}$ are the molar 6 fractions of cementite and ferrite respectively. At $570^{\circ} \mathrm{C}$, assuming a nominal atomic carbon 7 composition $\mathrm{X}_{\mathrm{c}}=1.78 \%(0.39 \% \mathrm{wt})$ in austenite at the beginning of the transformation and a 8 negligible content in ferrite, the lever rule imposes a molar fraction of cementite of $7.1 \%$ in pearlite. 9 Therefore, assuming that the Mn compositions inside cementite and ferrite are those determined by the thermodynamic approach, the overall manganese atomic composition $(2.46 \%)$ should have been higher than the nominal atomic composition (1.94\% expected from Table 1). This purely thermodynamic approach thus does not permit to verify a correct molar balance in the studied case.

This unsatisfactory situation has been avoided by Pandit and Bhadeshia [41] who in fact recommend first to calculate the $\gamma / \theta$ tie-line from the uniform carbon activity assumption. Once the $\mathrm{Mn}$ composition inside cementite is determined, they establish a new tie-line starting from this composition and passing through the bulk composition. (It is not an equilibrium tie-line). The corresponding Mn composition inside the growing ferrite is then deduced by extending this tie-line to the $\alpha / \alpha+\gamma$ phase boundary. Figure 9 shows the approximation of Pandit and Bhadeshia for the current steel. Mn composition in ferrite determined under this approximation is $\mathrm{U}_{\mathrm{Mn}}=1.80 \%$ which is even closer to our TEM measurement in ferrite. In that case, the solute molar balance is verified. 


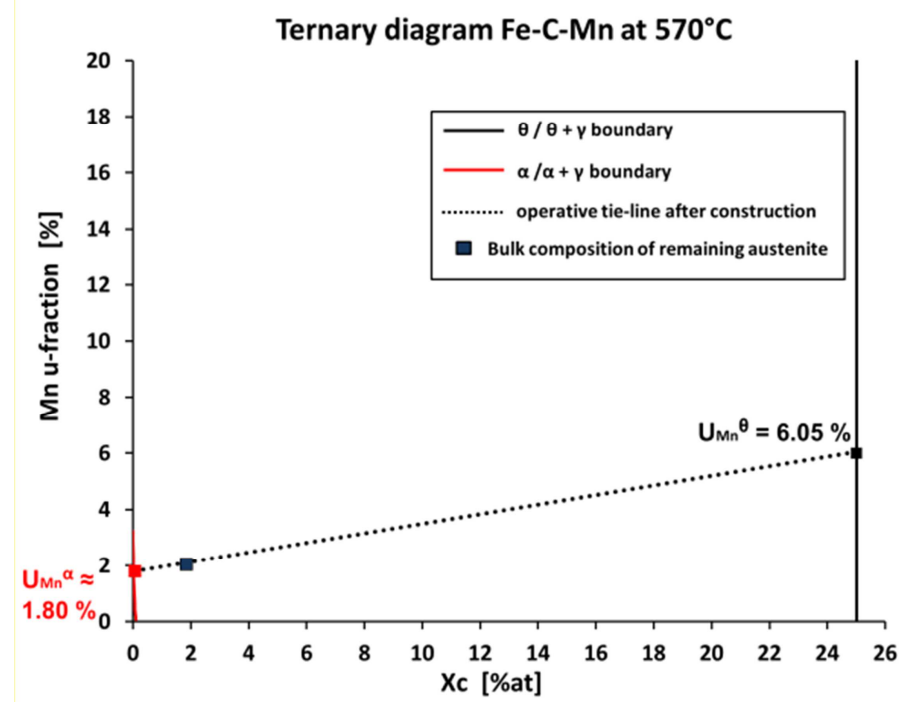

Figure 9: Isothermal section of the $\mathrm{Fe}-\mathrm{C}$-Mn ternary diagram at $570^{\circ} \mathrm{C}$. Red line represents the $\alpha$ I $\alpha+\gamma$ boundary. Black line represents the $\gamma+\theta / \theta$ boundary. The initial austenite composition is representedby the blue dot (input from TACSI simulation). The black dotted line represents the tie-line approximated according to Pandit and Bhadeshia [41]. It goes through the points representative of cementite composition and bulk austenite composition. Intersection with $\alpha / \alpha+\gamma$ boundary provides the estimated ferrite composition.

The thermodynamic approach using the carbon iso-activity is thus a convenient tool for the prediction of the solute composition within pearlite constituents (ferrite and cementite). However, this kind of approach is seldom used, even in the most recent investigations on pearlite. To our knowledge, only Pandit and Bhadeshia [41] have attempted to apply this reasoning to explain successfully the experimental results of Razik and Ridley. These investigations have been carried out on eutectoid steels in frame of isothermal treatments only. The present work seems to be the first to date to investigate with this model the pearlite transformation conditions after a pro-eutectoid transformation and thus at very low temperature.

\section{Ripening process of cementite during coiling and annealing}

\section{Basic thermodynamic and diffusion analysis}

We have seen in the previous sections that the phase compositions inherited from the transformation conditions are far from the local equilibrium conditions (considering the local carbon composition in pearlite $1.78 \%$ at). The differences are even higher at room temperature (even if the results of thermodynamic at such low temperatures should be considered carefully). The equilibrium composition in $\mathrm{Mn}$ and $\mathrm{Cr}$ at room temperature in cementite are $\mathrm{U}_{\mathrm{Mn}}=36$ and $\mathrm{U}_{\mathrm{Cr}}=4 \%$. The measurements of sample 2 are far lower revealing that the diffusivities of substitutional solutes are too 
1 low below coiling temperature range to obtain a uniform equilibrium composition profile through cementite. As central composition of cementite has not evolved, it means that substitutional solutes had even not the time to diffuse from the interfaces to the middle of cementite particles. Composition gradients from interfaces are thus observed over a limited distance (about 15-30 nm).

5

Mn composition profile measured in cementite after heating up to $700^{\circ} \mathrm{C}$ are almost flat and the constant value (about $\mathrm{U}_{\mathrm{Mn}}=10.0 \%$ in sample 3 ) is approaching the equilibrium composition $\left(\mathrm{U}_{\mathrm{Mn}}=\right.$ $14.3 \%$ ). It leads to the conclusion that, during heating, above a certain temperature, the Mn diffusivity is sufficient to permit the homogenization of Mn close to the equilibrium composition within a short period of time. $\mathrm{Cr}$ equilibrium composition $\left(\mathrm{U}_{\mathrm{Cr}}=2.7 \%\right)$ is nevertheless not reached, as $1.7 \%$ is measured in the cementite in sample 3 owing to a lower diffusivity. Similar observations were reported by Baltazar et al. [48] or by Phillipot et al. [33] who studied the Mn enrichment in cementite after heating up to $700^{\circ} \mathrm{C}$ at $1{ }^{\circ} \mathrm{C} . \mathrm{s}^{-1}$ of a $0.37 \mathrm{C}-2.53 \mathrm{Mn}$ wt. $\%$ steel (Mn content close to the studied steel). They measured $\mathrm{Mn}$ concentration in cementite by atom probe tomography close to $11 \% \mathrm{wt}$ $\left(\mathrm{U}_{\mathrm{Mn}}=12 \%\right)$ in very good agreement with our own observations. As in the studied case, Cr does not reach equilibrium after heating.

Mn diffusion lengths in cementite for both cooling from $570^{\circ} \mathrm{C}$ down to room temperature at $20^{\circ} \mathrm{C} \mathrm{h}^{-1}$ and heating up to $700^{\circ} \mathrm{C}$ at $3{ }^{\circ} \mathrm{C} \cdot \mathrm{s}^{-1}$ were estimated using the sole diffusion coefficient of $\mathrm{Mn}$ in cementite found in literature. $\mathrm{D}_{\mathrm{Mn}}^{\theta}$ has been extracted the MOBFE2 database of DICTRA (with TCFE9). For the sake of simplicity, isothermal holdings at $570^{\circ} \mathrm{C}$ and $700^{\circ} \mathrm{C}$, during $\mathrm{t}=24 \mathrm{~h}$ and $\mathrm{t}=$ $200 \mathrm{~s}$ were considered to estimate an upper value of $\sqrt{ } \mathrm{Dt}$. In both cases, diffusion lengths did not exceed $2 \mathrm{~nm}$. This is far lower than our observations (about 15-30 nm in the first case and larger than cementite half width in the second case).

Since $\mathrm{D}_{\mathrm{Mn}}^{\theta}$ provided by DICTRA software is obviously too weak, it must be reassessed, as did e.g. by Song [31]. This author proposes to multiply $D_{\mathrm{Mn}}^{\theta}$ by 5 in order to better calibrate its own experiments. More recently, Luo [36] needed to multiply it by 72 to make its DICTRA simulations consistent with their own experimental data. He noticed that this coefficient is still too low. In the present study, we propose to reassess this diffusion coefficient $\mathrm{D}_{\mathrm{Mn}}^{\theta}$ on the basis of our own experimental results. As done by Luo, simulations of Mn diffusion in pearlite will be conducted using the DICTRA software.

\section{DICTRA Simulations}

A model ternary Fe-C-Mn system is considered for the phase transformation calculations with DICTRA software (2017a version), using TCFE9 and MOBFE2 databases. Our equilibrium calculations have shown that other alloying element $(\mathrm{Si}$ and $\mathrm{Cr}$ ) do not affect significantly the 
1 chemical compositions of the phases and transformation temperatures. For this reason, the following

2 DICTRA simulations do not deal with the latter species.

3

4

A planar configuration representing a lamellar pearlite structure (half ferrite lamella in contact with a half cementite lamella) has been considered for the sake of simplicity, even if our observations are not all obtained in such simple geometrical configurations. Half-lamellar spacing and lamella thickness have been set respectively to 340 and $20 \mathrm{~nm}$ in accordance with our observations. The considered volumes are consistent with equilibrium calculations at $570^{\circ} \mathrm{C}(94.2$ and $5.8 \%$ vol of ferrite and cementite respectively).

Two successive thermal treatments have been simulated. The first one corresponds to the coiling treatment (between sample 1 and 2) and the second one to the interrupted annealing at $700^{\circ} \mathrm{C}$ (between sample 2 and 3). Initial Mn concentrations profiles in cementite and ferrite have been considered uniform and set to $\mathrm{U}_{\mathrm{Mn}}=6.25 \%$ in cementite and $\mathrm{U}_{\mathrm{Mn}}=1.70 \%$ in ferrite as observed experimentally in sample 1 (cf. Figure 3b). Phase and composition fields resulting from the first simulated treatment are used as initial conditions for the second simulations (by a field transfer).

Modeling space is discretized using unidimensional grids. 30 grid nodes have been distributed in both ferrite and cementite following a geometrical progression in both phases with ratio 0.8 and 1.02 respectively, in order to get a finer mesh near $\alpha / \theta$ interface. Both time and spatial discretization have to be optimized in order to reduce computation time without losing accuracy. Inappropriate simulation parameters could induce a significant decrease of the overall $\mathrm{Mn}$ concentration in the system. One points out that of curvature effects (Gibbs Thompson), morphological evolutions or interaction between particles (coarsening) were disregarded in our simulations. These contributions could be nonetheless taken into account to explain the significantly higher compositions measured inside the spheroidized extremity of the lamella shown in Figure 5. However, such a deeper investigation lies beyond the scope of this article.

The activation energies and the pre-exponential factors calculated with DICTRA for ferrite and cementite are summarized in Table 2. To obtain these values, the composition of the austenite grains have been considered $\left(\mathrm{X}_{\mathrm{c}}=1.78 \% \mathrm{a}_{\mathrm{a}}, \mathrm{U}_{\mathrm{MN}}=1.94 \%\right)$. In the case of ferrite, both parameters vary significantly with the temperature. An Arrhenius plot was drawn to deduce the values shown in Table 2 . 


\begin{tabular}{|c|c|c|}
\hline & Pre-exponential factor & Q $\left(\mathrm{kJ} . \mathrm{mol}^{-1}\right)$ \\
\hline Cementite $\theta$ & $1.05 \times 10^{-5}$ & 286.0 \\
\hline Ferrite $\alpha$ & 0.127 & 272.2 \\
\hline
\end{tabular}

Table 2: pre-exponential factor and activation energies of the Mn diffusion coefficient in cementite and ferrite, respectively.

Mn diffusion coefficient in cementite has been tuned to best reproduce our experimental observations. In this procedure, only pre-exponential term has been modified so far (not the activation energy) and multiplied by 2000 . This value is consistent with the respective remarks of Song and Luo [31, 36]. Mn diffusion coefficient in ferrite has been taken from the database and has not been modified, since it is considered well validated.

\section{Simulation results}

Figure 11a shows the composition profiles calculated in cementite considering a slow cooling representative of the coiling operation (from sample 1 to sample 2) and Figure 11b the composition profiles after heating from room temperature $\left(25^{\circ} \mathrm{C}\right)$ to $700^{\circ} \mathrm{C}$ at $3{ }^{\circ} \mathrm{C} \cdot \mathrm{s}^{-1}$ (from sample 2 to sample 3 ). For the sake of comparison, calculated composition profiles have been compared to experimental measurements in cementite. In the second simulation, the expected equilibrium composition at $700^{\circ} \mathrm{C}$ is represented by a dotted line. It corresponds to the partition expected in the sole pearlite sub-system.

It should first be noticed that in both cases, interface remains fixed during the inter-diffusion process as carbon solubility in ferrite and in pearlite does not vary much with temperature. In Figure 11a, the composition profile shows a steep gradient in cementite at the interface (extended over about $15 \mathrm{~nm}$ ) whereas the middle of the cementite particle is not enriched (still at 6.25\%). Mn interfacial composition predicted by DICTRA is $\mathrm{U}_{\mathrm{Mn}}=12.7 \%$, that is far lower than that equilibrium composition expected at room temperature $\left(\mathrm{U}_{\mathrm{Mn}} \approx 36 \%\right)$ consistently with the low Mn diffusivity in this temperature range $\left(\mathrm{T}<570^{\circ} \mathrm{C}\right)$. The $\mathrm{Mn}$ composition profile inside ferrite shows a depletion over $40 \mathrm{~nm}$ from the interface, similarly to the TEM measurements, except that particle studied in sample 2 is located in a Mn microsegregated band, involving a Mn concentration twice higher $\left(\mathrm{U}_{\mathrm{Mn}} \approx 4 \%\right)$. It is the reason why the experimental Mn profile is higher than the simulated one in the ferrite matrix. Hence, calibrating Mn diffusion coefficient in cementite has permitted to reproduce consistently our experimental observations. 


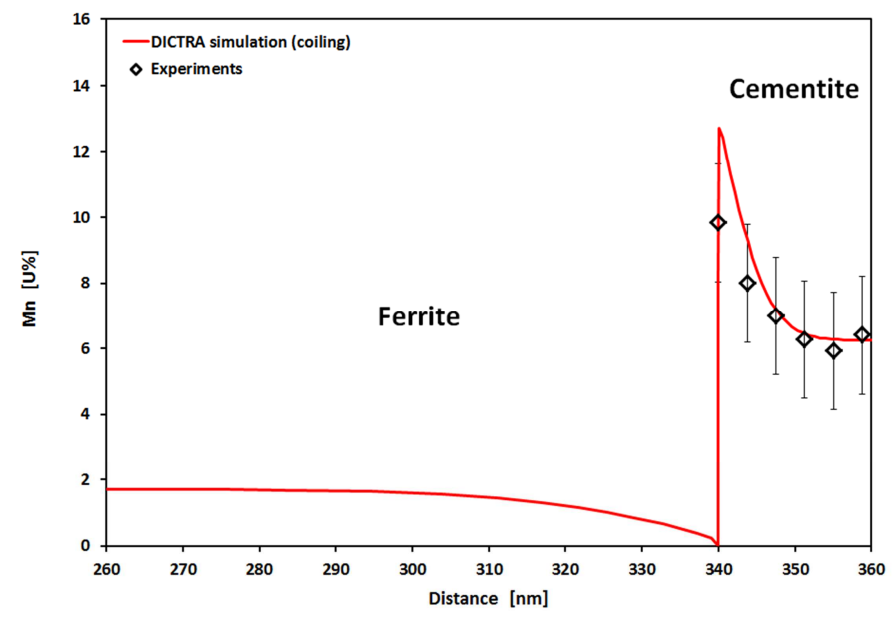

(a)

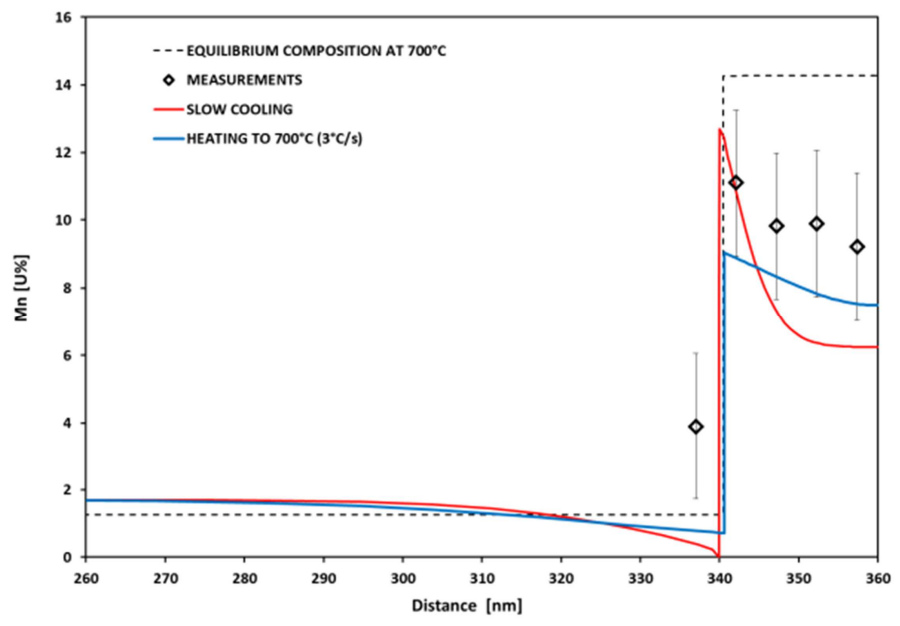

(b)

Figure 11: Results of DICTRA simulations (a) Mn concentration profiles in ferrite and cementite after cooling from $570^{\circ} \mathrm{C}$ down to room temperature at $20^{\circ} \mathrm{C} . \mathrm{h}^{-1}$ (continuous red line); (b) Mn concentration profiles in ferrite and cementite at $700^{\circ} \mathrm{C}$ after slow heating $\left(3^{\circ} \mathrm{C} . \mathrm{s}^{-1}\right)$ from room temperature (continuous blue line). The continuous red line corresponds to the initial composition profile considered for the reheating simulation. Dashed line represents the equilibrium composition expected in the pearlite sub-system at $700^{\circ} \mathrm{C}$. Symbols indicate in both cases TEM composition measurements in cementite obtained in sample 2 and sample 3 for the sake of comparison.

The reliability of our reassessment was confirmed by simulating the composition evolution in cementite during reheating to $700^{\circ} \mathrm{C}$. Figure $11 \mathrm{~b}$ shows that the calculated profile after heating is far flatter than after coiling. Low calculated composition gradients are in excellent agreement with our experimental observations. Only interface compositions are slightly lower than observed experimental values. The presence of a microsegregation could explain this difference.

Our DICTRA simulations show that it is possible to explain and predict experimental $\mathrm{Mn}$ concentration profiles inside cementite during coiling and heating by simple diffusion calculations with local equilibrium at ferrite/cementite interface. When using MOBFE2 database, Mn diffusion 
1 coefficient in cementite has to be multiplied by a factor 2000 to obtain consistent composition profiles

2 and gradients.

\section{Conclusions}

4 Cementite composition in a ferrite-pearlite steel dedicated to the production of DP steels has been

5 investigated along the manufacturing process, i.e. after hot-rolling and during annealing. By coupling

6 TEM investigations and Thermocalc / DICTRA modeling, we have explained how cementite is

7 progressively enriched in manganese.

8 This enrichment begins at the pearlite transformation stage. The uniform enrichment we have

9 measured in our cementite particle (about $7 \%$ ) can be well explained and thus predicted by the model

10 proposed by Hutchinson [28] considering the simultaneous local equilibria between ferrite and

11 austenite and cementite and austenite during the pearlite transformation. To the best knowledge of the

12 authors, this work is the first to validate the model for a pearlite transformation after a pro-eutectoid

13 transformation and thus at very low temperature. Nevertheless, we have shown that in the studied case

14 the strict application of transformation conditions does not lead to a satisfactory mass balance. As

15 suggested by Pandit et al. [41], a simplified version is shown to overcome this difficulty. This

16 enrichment stage is rarely taken into account when addressing cementite composition in ferrite-pearlite 17 steels.

18 Compositions inherited from phase transformation are far from equilibrium. During subsequent coiling

19 operation and annealing, cementite enrichment in manganese will continue. Our DICTRA calculations

20 show that observed composition profile can be nicely understood and reproduced considering simple

21 diffusion calculations with local equilibrium at ferrite/cementite interface. Nevertheless, the known

22 diffusion coefficient of manganese in cementite must be revised to explain composition gradients

23 observed after coiling and after interrupted annealing. The simulations have also enabled a better

24 understanding of operative interface conditions between ferrite and cementite during the thermal 25 treatments.

26 We have finally showed that both thermodynamic approach of pearlite phase transformation and diffusion calculation must be coupled to follow seamlessly manganese composition gradients in cementite all along the manufacturing process. Knowing the exact composition profile is a prerequisite to predict accurately austenite transformation kinetics and thus final DP microstructures. One should

30 however admit that in the studied slow annealing conditions, cementite composition is close to the 31 equilibrium at $700^{\circ} \mathrm{C}$ reducing possible inheritance effects. It is likely that this conclusion does not hold anymore in the case of fast annealing conditions. 


\section{Acknowledgements}

2 This research was funded by Centre National de la Recherche Scientifique (CNRS) and by

3 ArcelorMittal Maizières les Metz (Product Research Centre). The Laboratory of Excellence on Design

4 of Alloy Metals for low-mAss Structures (Labex DAMAS) from Université de Lorraine (France) is

5 also fully acknowledged for its support.

\section{Conflicts of Interest}

7 The authors declare no conflict of interest.

\section{References}

10 [1] Speich, G.R., Demarest, V.A., Miller, R.L., 1981. Formation of Austenite During Intercritical

11 Annealing of Dual-Phase Steels. Metallurgical and Materials Transactions A 12, 1419-1428.

12 https://doi.org/10.1007/BF02643686

[2] Kulakov, M., Poole, W.J., Militzer, M., 2013. The Effect of the Initial Microstructure on

15 Recrystallization and Austenite Formation in a DP600 Steel. Metallurgical and Materials Transactions

16 A 44, 3564-3576. https://doi.org/10.1007/s11661-013-1721-z

[3] Allam, T., Abbas, M., 2015. Mechanical Properties, Formability, and Corrosion Behavior of Dual Phase Weathering Steels Developed by an Inter-Critical Annealing Treatment. steel research international 86, 231-240. https://doi.org/10.1002/srin.201400033

[4] Hofmann, H., 2009. Advanced Cold Rolled Steels for Automotive Applications. Steel Research

[5] De Moor, E., Matlock, D.K., Speer, J.G., Merwin, M.J., 2011. Austenite stabilization through manganese enrichment. Scripta Materialia 64, 185-188.

https://doi.org/10.1016/j.scriptamat.2010.09.040

[6] Movahed, P., Kolahgar, S., Marashi, S.P.H., Pouranvari, M., Parvin, N., 2009. The effect of intercritical heat treatment temperature on the tensile properties and work hardening behavior of 
2 [7] Erdogan, M., 2003. Effect of austenite dispersion on phase transformation in dual phase steel.

3 Scripta Materialia 48, 501-506. https://doi.org/10.1016/S1359-6462(02)00500-6

4

5 [8] Jacques, P., Delannay, F., Cornet, X., Harlet, P., Ladriere, J., 1998. Enhancement of the

6 mechanical properties of a low-carbon, low-silicon steel by formation of a multiphased microstructure

7 containing retained Austenite. Metallurgical and Materials Transactions A 29, 2383-2393.

8 https://doi.org/10.1007/s11661-998-0114-1

[9] Allain, S.Y.P., Bouaziz, O., Pushkareva, I., Scott, C.P., 2015. Towards the microstructure design of DP steels: A generic size-sensitive mean-field mechanical model. Materials Science and Engineering:

[10] Agren, J., Abe, H., Suzuki, T., Sakuma, Y., 1986. The dissolution of cementite in a low carbon

https://doi.org/10.1007/BF02643980

[11] Martín, S.D., Cock, de T., García-Junceda, A., Caballero, F.G., Capdevila, C., de Andrés, C.G., 2008. Effect of heating rate on reaustenitisation of low carbon niobium microalloyed steel. Materials

Science and Technology 24, 266-272. https://doi.org/10.1179/174328408X265640

[12] Arlazarov, A., Gouné, M., Bouaziz, O., Hazotte, A., Petitgand, G., Barges, P., 2012. Evolution of microstructure and mechanical properties of medium Mn steels during double annealing. Materials

[13] Humphreys, F.J., Hatherly, M., 2004. Recrystallization and related annealing phenomena, 2nd ed. ed. Elsevier, Amsterdam ; Boston. https://doi.org/10.1007/BF02658671

[15] Huang, J., Poole, W.J., Militzer, M., 2004. Austenite formation during intercritical annealing. 
1 [16] Li, P., Li, J., Meng, Q., Hu, W., Xu, D., 2013. Effect of heating rate on ferrite recrystallization

2 and austenite formation of cold-roll dual phase steel. Journal of Alloys and Compounds 578, 320-327.

3 https://doi.org/10.1016/j.jallcom.2013.05.226

4

5 [17] Chbihi, A., Barbier, D., Germain, L., Hazotte, A., Gouné, M., 2014. Interactions between ferrite

6 recrystallization and austenite formation in high-strength steels. Journal of Materials Science 49,

7 3608-3621. https://doi.org/10.1007/s10853-014-8029-2

9 [18] Barbier, D., Germain, L., Hazotte, A., Gouné, M., Chbihi, A., 2015. Microstructures resulting

10 from the interaction between ferrite recrystallization and austenite formation in dual-phase steels.

11 Journal of Materials Science 50, 374-381. https://doi.org/10.1007/s10853-014-8596-2

[19] Ollat, M., Massardier, V., Fabregue, D., Buscarlet, E., Keovilay, F., Perez, M., 2017. Modeling of the Recrystallization and Austenite Formation Overlapping in Cold-Rolled Dual-Phase Steels During Intercritical Treatments. Metallurgical and Materials Transactions A 48, 4486-4499.

[20] Garcia, C.I., De Ardo, A.J., 1981. Formation of austenite in 1.5 pct Mn steels. Metallurgical

Transactions A 12, 521-530. https://doi.org/10.1007/BF02648551

[21] Caballero, F.G., Capdevila, C., Andrés, C.G. de, 2003. An Attempt to Establish the Variables

That Most Directly Influence the Austenite Formation Process in Steels. ISIJ International 43, 726

735. https://doi.org/10.2355/isijinternational.43.726

[22] Razik, N.., Lorimer, G.., Ridlel, N., 1974. An investigation of manganese partitioning during the austenite-pearlite transformation using analltical electron microscopl. Acta Metallurgica 22, 12491258. https://doi.org/10.1016/0001-6160(74)90138-2

[23] Razik, N.A., Lorimer, G.W., Ridley, A.N., 1976. Chromium partitioning during the austenitepearlite transformation. Metallurgical Transactions A 7, 209-214. https://doi.org/10.1007/BF02644458

[24] Al-Salman, S.A., Lorimer, G.W., Ridley, N., 1979. Pearlite growth kinetics and partitioning in a 
1 [25] Chance, J., Ridley, N., 1981. Chromium partitioning during isothermal transformation of a

2 eutectoid steel. Metallurgical Transactions A 12, 1205-1213. https://doi.org/10.1007/BF02642334

3

[26] Hillert, M. In: Aaronson HI, Laughlin DE, Sekerka RF, Wayman CM, editors. Solid-solid phase transformations. Warrendale (PA): TMS-AIME; 1982. p. 789-806.

[27] Coates, D.E., 1973. Diffusional growth limitation and hardenability. Metallurgical Transactions 4,

[28] Hutchinson, C.R., Hackenberg, R.E., Shiflet, G.J., 2004. The growth of partitioned pearlite in Fe-

C-Mn steels. Acta Materialia 52, 3565-3585. https://doi.org/10.1016/j.actamat.2004.04.010

[29] Babu, S.S., Hono, K., Sakurai, T., 1993. APFIM studies on martensite tempering of Fe-C-Si-Mn

low alloy steel. Applied Surface Science 67, 321-327. https://doi.org/10.1016/0169-4332(93)90333-7

[30] Ghosh, G., Olson, G.B., 2002. Precipitation of paraequilibrium cementite: Experiments, and thermodynamic and kinetic modeling. Acta Materialia 50, 2099-2119. https://doi.org/10.1016/S1359$\underline{6454(02) 00054-X}$

[31] Song, W., Choi, P.-P., Inden, G., Prahl, U., Raabe, D., Bleck, W., 2014. On the Spheroidized Carbide Dissolution and Elemental Partitioning in High Carbon Bearing Steel 100Cr6. Metallurgical and Materials Transactions A 45, 595-606. https://doi.org/10.1007/s11661-013-2048-5

[32] Hwang, H., De Cooman, B.C., 2016. Influence of the Initial Microstructure on the Spheroidization of SAE 52100 Bearing Steel. steel research international 87, 112-125. https://doi.org/10.1002/srin.201400591

[33] Philippot, C., Hoummada, K., Dumont, M., Drillet, J., Hebert, V., Maugis, P., 2015. Influence of a 2-D defect on the partitioning during the formation of a cementite particle in steels. Computational Materials Science 106, 64-68. https://doi.org/10.1016/j.commatsci.2015.04.020

[34] Miyamoto, G., Oh, J., Hono, K., Furuhara, T., Maki, T., 2007. Effect of partitioning of Mn and Si on the growth kinetics of cementite in tempered $\mathrm{Fe}-0.6$ mass\% C martensite. Acta Materialia 55, 5027-5038. https://doi.org/10.1016/j.actamat.2007.05.023

[35] Tu, Y., Huang, L., Wang, X., Zhou, X., Fang, F., Jiang, J., 2016. Effect of Si and Mn Interactions on the Spheroidization and Coarsening Behavior of Cementite During Annealing in Severe Cold- 
1 Drawn Pearlitic Steel. Metallurgical and Materials Transactions A 47, 254-259.

2 https://doi.org/10.1007/s11661-015-3219-3

3

4 [36] Luo, H., Liu, J., Dong, H., 2016. A Novel Observation on Cementite Formed During Intercritical

5 Annealing of Medium Mn Steel. Metallurgical and Materials Transactions A 47, 3119-3124.

6 https://doi.org/10.1007/s11661-016-3448-0

7

[37] Arruabarrena, J., López, B., Rodriguez-Ibabe, J.M., 2014. Influence of Prior Warm Deformation on Cementite Spheroidization Process in a Low-Alloy Medium Carbon Steel. Metallurgical and

Materials Transactions A 45, 1470-1484. https://doi.org/10.1007/s11661-013-2066-3

[38] Owen, W. S. The effect of silicon on the kinetics of tempering. Transactions of the American

Society for Metals, 46, 812-829.

[39] Jang, J.H., Kim, I.G., Bhadeshia, H.K.D.H., 2009. Substitutional solution of silicon in cementite:

A first-principles study. Computational Materials Science 44, 1319-1326.

https://doi.org/10.1016/j.commatsci.2008.08.022

[40] Tian, Y.L., Kraft, R.W., 1987. Mechanisms of Pearlite Spheroidization. Metallurgical

Transactions A 18, 1403-1414. https://doi.org/10.1007/BF02646654

[41] Pandit, A.S., Bhadeshia, H.K.D.H., 2011. Diffusion-controlled growth of pearlite in ternary steels. Proceedings of the Royal Society A: Mathematical, Physical and Engineering Sciences 467, 2948-2961. https://doi.org/10.1098/rspa.2011.0165

[42] Zurob, H.S., Hutchinson, C.R., Béché, A., Purdy, G.R., Bréchet, Y.J.M., 2008. A transition from local equilibrium to paraequilibrium kinetics for ferrite growth in $\mathrm{Fe}-\mathrm{C}-\mathrm{Mn}$ : A possible role of interfacial segregation. Acta Materialia 56, 2203-2211. https://doi.org/10.1016/j.actamat.2008.01.016

[43] Chen, H., van der Zwaag, S., 2016. The Effect of Interfacial Element Partitioning on Ferrite and Bainite Formation. JOM 68, 1320-1328. https://doi.org/10.1007/s11837-016-1848-7

[44] Perlade, A., Grandemange, D., Iung, T., 2005. Application of microstructural modelling for 
1 [45] Iung, T., Kandel, M., Quidort, D., de Lassat, Y., 2003. Physical modelling of phase

2 transformations in high strength steels. Revue de Métallurgie 100, 173-181.

3 https://doi.org/10.1051/metal:2003105

4

5 [46] Marder, A.R., Bramfitt, B.L., 1975. Effect of continuous cooling on the morphology and kinetics

6 of pearlite. Metallurgical Transactions A 6, 2009-2014. https://doi.org/10.1007/BF03161825

[47] Panahi, D., Bai, Y.F., Zurob, H.S., Purdy, G.R., Hutchinson, C.R., Bréchet, Y., 2011. Kinetic

Transitions during Non-Partitioned Ferrite Growth in Fe-C-Mn Alloys. Solid State Phenomena 172-

174, 539-548. https://doi.org/10.4028/www.scientific.net/SSP.172-174.539

[48] Baltazar Hernandez, V.H., Nayak, S.S., Zhou, Y., 2011. Tempering of Martensite in Dual-Phase

Steels and Its Effects on Softening Behavior. Metallurgical and Materials Transactions A 42, 3115-

3129. https://doi.org/10.1007/s11661-011-0739-3

15

[49] Ridley, N., 1984. A Review of the Data on the Interlamellar Spacing of Pearlite. Metallurgical and Materials Transactions A 15, 1019-1036. https://doi.org/10.1007/BF02644694

[50] RT DeHoff and FN Rhines “Quantitative Microscopy” (1972)

[51] Enomoto, M., Lange, W.F., Aaronson, H.I., 1986. The kinetics of ferrite nucleation at austenite grain edges in Fe-C and Fe-C-X alloys. Metallurgical Transactions A 17, 1399-1407. https://doi.org/10.1007/BF02650121

[52] Enomoto, M., Aaronson, H.I., 1986. On the critical nucleus composition of ferrite in an Fe-C-Mn alloy. Metallurgical Transactions A 17, 1381-1384. https://doi.org/10.1007/BF02650119

[53] Tanaka, T., Aaronson, H.I., Enomoto, M., 1995. Nucleation kinetics of grain boundary allotriomorphs of proeutectoid ferrite in Fe-C-Mn-X2 alloys. Metallurgical and Materials Transactions A 26, 547-559. https://doi.org/10.1007/BF02663905

[54] Enomoto, M., Aaronson, H.I., 1986. Nucleation kinetics of proeutectoid ferrite at austenite grain boundaries in Fe-C-X alloys. Metallurgical Transactions A 17, 1385-1397. https://doi.org/10.1007/BF02650120 
1 [55] Yoon, S., Lee, S.-J., 2014. Improved Thermodynamic Formula for 2 Austenite/(Austenite+Cementite) Phase Boundary in Low Alloy Steels. ISIJ International 54, 14533 1455. https://doi.org/10.2355/isijinternational.54.1453

4

5 [56] Lee, J.W., Thompson, S.W., Varughese, R., Howell, P.R., 1993. The interaction between 6 proeutectoid ferrite and austenite during the isothermal transformation of two low-carbon steels? a 7 new model for the decomposition of austenite. Journal of Materials Science 28, 4571-4577. 8 https://doi.org/10.1007/BF00414244 9

10 [57] Embury, J.., Fisher, R.., 1966. The structure and properties of drawn pearlite. Acta Metallurgica 11 14, 147-159. https://doi.org/10.1016/0001-6160(66)90296-3

12

13 [58] Freshwater, I.J., 1996. Simplified theories of flat rolling-I. The calculation of roll pressure, roll 14 force and roll torque. International Journal of Mechanical Sciences 38, 633-648. 15 https://doi.org/10.1016/S0020-7403(96)80006-3

16 